I Universidade Nacional de Quilmes (UNQ),

Departamento de Ciencias Sociales, Buenos Aires, Argentina

ablanco@unq.edu.ar

II Universidade Federal do Rio de Janeiro (UFRJ),

Departamento de Sociologia, Rio de Janeiro, RJ, Brasil

antoniobrasiljr@gmail.com

\title{
A CIRCULAÇÃO INTERNACIONAL DE FLORESTAN FERNANDES
}

A análise da obra e da trajetória de Florestan Fernandes já conta com enorme acervo de trabalhos. As condicionantes sociais de sua carreira profissional (Miceli, I989; Blanco \& Jackson, 20I4a), o engate de sua origem "plebeia" com uma certa orientação teórica de análise (Cohn, 2005), seu papel na renovação da linguagem sociológica e suas conexões com o processo mais amplo de modernização social e cultural (Arruda, 200I), suas contribuições para a formação de uma perspectiva teórico-metodológica sobre a sociedade brasileira, compartilhada ao longo das várias gerações de cientistas sociais (Bastos, 2002), o potencial teórico de suas formulações para os problemas do presente (Bastos, 20 I I; Brasil Jr., 20I3; Brasil Jr. \& Botelho, 20I7) - essas são algumas das múltiplas possibilidades de abordar o seu lugar nas ciências sociais brasileiras.

Neste artigo, investigamos o caso de Florestan Fernandes de um ângulo diferente e até aqui pouco explorado: sua circulação internacional. ${ }^{\mathrm{I}}$ Se já acumulamos considerável conhecimento sobre as relações do autor com a sociedade brasileira, acreditamos que o mapeamento de sua circulação fora do país, bem como de alguns de seus produtos intelectuais, permitirá trazer novas questões e perspectivas de análise. Em pesquisa recente, que comparou o grau de articulação internacional dos projetos acadêmicos desenvolvidos por Gino Germani, Luiz de Aguiar Costa Pinto e Florestan Fernandes, nas cidades de Buenos Aires, Rio de Janeiro e de São Paulo, respectivamente, já foram trazidos elementos importantes nessa direção (Blanco \& Jackson, 20I4b), que procuramos 
aprofundar para o caso específico de Fernandes. A fim de revelar essas novas dimensões, neste primeiro esforço de análise que tentamos aqui, exploramos três eixos fundamentais: (I) a identificação das especificidades da circulação internacional de Florestan Fernandes à luz da trajetória modal dos sociólogos de sua geração que lideraram a formação da disciplina na América Latina; (2) o mapeamento da circulação de sua produção intelectual fora do Brasil, tomando como material de análise seus artigos publicados em revistas estrangeiras, sua participação em eventos científicos internacionais e as resenhas de suas obras feitas no exterior; (3) o delineamento de algumas hipóteses explicativas, as quais incidem especialmente na necessidade de distinguir conceitualmente os termos "internacionalização" e "circulação internacional", a fim de explicar o caso de Florestan Fernandes. No final do texto, trazemos algumas indicações a respeito dos possíveis efeitos de sua circulação internacional em sua teorização sociológica da América Latina.

\section{TRAJETÓRIA MODAL E O CASO DE FLORESTAN FERNANDES}

A circulação internacional (e regional) de Florestan Fernandes e de sua produção intelectual ganha fôlego após o golpe de ig64, quando seu empreendimento intelectual se vê ameaçado pelo avanço do fechamento político. Um segundo condicionante dessa maior circulação internacional serão suas estadas acadêmicas nos Estados Unidos (na Columbia University, em Nova York, e na Yale University, em New Haven) e sua posterior permanência no Canadá, depois da aposentadoria compulsória, em I969. ${ }^{2}$ Em comparação com a trajetória modal dos sociólogos contemporâneos a Fernandes que também tiveram um papel destacado no período de formação das ciências sociais na América Latina, sua circulação internacional é mais tardia. Todos eles - José Medina Echavarría [1903-I977], Gino Germani [I9I I-I979], Luiz de Aguiar Costa Pinto [1920-2002], Aldo Solari [I922-I989], Pablo González Casanova [1922] e Orlando Fals Borda [1925-2008] - exibem trajetórias de formação e de atuação profissional de alta mobilidade ${ }^{3}$ em um espaço acadêmico em rápido processo de internacionalização, como resultado das iniciativas dos diferentes organismos internacionais criados depois da Segunda Guerra Mundial (Unesco, OEA, ONU, Cepal) e das principais instituições de mecenato acadêmico (fundações Ford e Rockefeller). Essa mobilidade, como veremos em seguida, condicionou favoravelmente a circulação e a recepção de suas obras - o contrário teria acontecido precisamente com as de Fernandes, que, podemos conjecturar, obedeceu à sua menor circulação internacional até meados dos anos ig6o.

A maioria deles passou por experiências de formação no exterior (Estados Unidos, Alemanha e França), ${ }^{4}$ o que lhes permitiu acumular um capital linguístico e social que, mais tarde, mobilizariam em distintas frentes de atuação intelectual e profissional (no mercado editorial, como editores e tradutores, ${ }^{5}$ nas negociações com as instituições internacionais de financiamento e no emergente mercado de 
postos da nova burocracia internacional das agências de planejamento econômico, social e educacional). Tiveram papéis destacados nos principais centros regionais/internacionais de ensino, como a Facultad Latinoamericana de Ciencias Sociales (Flacso), e de pesquisa, como o Centro Latino-Americano de Pesquisas em Ciências Sociais (Clapcs), e em organismos de informação e de planejamento, como a Comisión Económica para América Latina (Cepal) e o Instituto Latinoamericano de Planificación Económica y Social (Ilpes). Participaram em projetos coletivos de pesquisa de caráter internacional. Todos integraram o comitê diretor da Revista Latinoamericana de Sociología (RLS), do Instituto Torcuato Di Tella, e a maioria integrou outra revista regional, América Latina, do Clapcs. Vários deles foram membros ativos - chegando a ocupar posições de comando político - da International Sociological Association (ISA). ${ }^{6}$ Dado esse alto grau de mobilidade de suas trajetórias, todos publicaram em editoras e revistas de distintos países da região, especialmente do México e da Argentina, países que, naquele momento, contavam com o mercado de editoras e de revistas especializadas em ciências sociais de língua espanhola mais importante da América Latina.

Diferentemente deles, Fernandes esteve praticamente ausente das principais apostas coletivas dos sociólogos "científicos" no cone sul. Não participou das instituições regionais de ensino e de pesquisa (Flacso e Clapcs), não enviou estudantes à Flacso, ainda que o Brasil, junto com o México, a Argentina e o Chile, tenha sido um dos principais usuários dessa instituição. ${ }^{7}$ Não por acaso, a cidade de São Paulo tampouco foi a sede dos seminários e congressos internacionais que durante o período reuniram a flor e a nata das ciências sociais latino-americanas ${ }^{8}$ - embora Fernandes e seu "grupo" da cadeira de sociologia I da USP tenham participado de vários (e importantes) eventos patrocinados pelo Clapcs no Rio de Janeiro. A geografia cultural desses eventos, concentrada nas cidades de Santiago de Chile, Buenos Aires e Rio de Janeiro, revela os centros de gravitação dessa aliança intelectual em curso. Fernandes tampouco deu aulas ou conferências na Flacso, como fizeram alguns de seus contemporâneos. ${ }^{9}$ Não integrou o comitê de América Latina, a revista publicada pelo Clapcs. Somente em meados da década de i 960 é que ele se integrou ao comitê da Revista Latinoamericana de Sociología (RLS), fundada por Gino Germani em I965, embora não tenha chegado a publicar ali nenhum artigo. ${ }^{\text {Io }}$ No entanto, a escola de sociologia liderada por Fernandes na USP esteve muito bem representada na RLS, mediante a colaboração de seus principais ex-alunos ou colaboradores próximos, como Fernando Henrique Cardoso, Octavio Ianni, Luciano Martins, Francisco Weffort, Marialice Mencarini Foracchi e Leôncio Martins Rodrigues. Fernandes tampouco participou das pesquisas coletivas sobre América Latina, como "Estratificação e mobilidade social em quatro países da América Latina (Argentina, Brasil, Chile e Uruguai)", levada a cabo por Clapcs, Flacso e o Instituto de Sociologia da Universidade de Buenos Aires, nem participou, como alguns de seus congêneres, da emergente - e muito norte-americanizada organização internacional da disciplina. 
É inegável que a fraca integração de Fernandes a essa comunidade intelectual latino-americana das ciências sociais em formação condicionou a perspectiva cognitiva de sua obra, toda ela concentrada na sociedade brasileira diferentemente de seus coetâneos, que se lançaram a exames abrangentes e comparativos sobre a América Latina, atitude certamente condicionada tanto por sua participação em organizações regionais de ensino e pesquisa (Flacso e Clapcs) como também por suas atuações profissionais em organismos internacionais (Cepal, Ilpes, Unesco, etc.). A condição de estrangeiros de vários deles - Medina Echavarría, Germani, Peter Heintz [I920-I983] e Rodolfo Stavenhagen [I932-20I6] - operou sem dúvida como um reforço dessas disposições de posição. José Medina Echavarría escreveu dois livros importantes sobre América Latina, El desarrollo social de América Latina en la pos-guerra (1963) e Consideraciones sociológicas sobre el desarrollo económico en América latina (I964), como funcionário da Cepal, o primeiro deles preparado em colaboração com Enzo Faletto e Luis Ratinoff, graduados na Escuela Latinoamericana de Sociología da Flacso. Jorge Graciarena [I922-20I4] reuniu em Poder y clases sociales en el desarrollo de América latina (1967) trabalhos escritos como funcionário da Unesco em três cidades da América Latina: Bogotá, Montevidéu e Rio de Janeiro. Un paradigma del desarrollo sociológico con especial referencia a América Latina (I970), do sociólogo suíço Peter Heintz, resultou de sua prolongada carreira profissional como funcionário da Unesco durante a década de I950, em distintos países da América Latina, e que incluiu a direção da Escuela Latinoamericana de Sociología da Flacso entre ig6o e i965. Com vínculos frequentes com os distintos organismos internacionais e as agências filantrópicas norte-americanas de financiamento da ciência social (fundações Ford e Rockefeller), e com ativa participação nas distintas iniciativas regionais, Gino Germani adotou, desde muito cedo, um enfoque "latino-americano" e comparado. O arco de sua produção latino-americana compreende seus estudos tanto sobre a urbanização, a estratificação social e a mobilidade social na América Latina como suas análises relativas ao avanço da disciplina, reunidos em Política y sociedad en una época de transición (I962), Sociología de la modernización. Estudios teóricos, metodológicos y aplicados a América latina (I969), Urbanización, desarrollo y modernización. Un enfoque histórico y comparativo (I976) e em La sociología en América Latina (I964). Também Fernando Henrique Cardoso, um dos principais discípulos de Florestan Fernandes, adotou uma perspectiva latino-americana quando se radicou em Santiago de Chile, em I964, depois do golpe, como funcionário do Ilpes e professor da Flacso, tal como revelam seus trabalhos reunidos em Cuestiones de sociología del desarrollo en América Latina (1968) e Dependencia y desarrollo en América Latina (1969), em coautoria com Enzo Faletto. Um enfoque latino-americano também está presente em La sociología del cambio y el cambio de la sociología (1963) e Estructura de clases y cambio social (I964), de Luiz de Aguiar Costa Pinto, que entre I957 e I96I dirigiu um centro regional de pesquisas, o Clapcs, órgão 
que também lançou a primeira revista "latino-americana" de ciências sociais, América Latina. Rodolfo Stavenhagen, que foi secretário-geral do Clapcs no Rio de Janeiro entre ig6 I e i964, publicou ao final desse período de funcionário internacional o seu trabalho mais célebre, Siete tesis equivocadas sobre América Latina (1965). Também Aldo Solari adotou um enfoque latino-americano e comparativo de forma correlata a sua integração às instituições regionais das ciências sociais e aos organismos internacionais, sobretudo os trabalhos que publicou como funcionário da Cepal e do Ilpes, como Educación, recursos humanos y desarrollo en América Latina (I968), El cambio social y la política de desarrollo social en América Latina (I969), Algunas reflexiones sobre la juventud latinoamericana (I97 I) e Problemas del desarrollo social de América Latina (1974).

No quadro I (ver página 74), apresentamos os livros publicados por sociólogos contemporâneos a Florestan Fernandes entre I940 e I975 em países/cidades da América Latina distintos do país de nascimento ou residência do autor. A informação contida no quadro permite advertir, em princípio, que a maioria dos livros publicados por esses sociólogos em países/cidades da América Latina distintos do país de nascimento ou residência dos autores listados se localiza entre finais da década de i950 e inícios da década de i970. Nesse período, precisamente, foram criados os principais instrumentos de produção e de reprodução - centros de ensino e pesquisa, revistas e congressos - de um espaço transnacional e de uma aliança intelectual que atingiu a trajetória e a produção de seus principais beneficiários, ao lhes propiciar o acesso a circuitos de atuação profissional e de circulação regional da sociologia. As editoras em que esses livros foram publicados estavam sob o controle (direto ou indireto) dos distintos integrantes dessa aliança, ${ }^{\text {II }}$ operando, portanto, como instrumentos de reprodução ampliada do capital intelectual do grupo.

Certamente, a comparativamente mais alta e diversa circulação de Medina Echavarría - publicou cinco livros no México, um no Chile, dois na Argentina e um no Uruguai - pode ser entendida à luz de sua grande mobilidade geográfica - entre I939 e I977, viveu em quatro países da América Latina: México, Colômbia, Porto Rico e Chile -, mobilidade em parte condicionada por sua condição de estrangeiro e de funcionário de organismos internacionais (Cepal e Ilpes). O mesmo se aplica ao caso de Aldo Solari (Cepal e Ilpes). Depois de seu primeiro livro na Argentina, publicado em I955, Germani publicou o segundo e o terceiro livro no México e no Brasil (I956 e I960, respectivamente, conforme o quadro), mas também, entre i950 e I968, publicou seis artigos na Revista Mexicana de Sociología, o que revela uma precoce circulação regional. Embora tenha lançado todos os seus primeiros livros no México, entre I962 e I965, Pablo González Casanova publicou quatro artigos nas principais revistas de sociologia da região, duas do Brasil (América Latina, publicação do Clapcs) e duas da Argentina (Desarrollo Económico e Revista Latinoamericana de Sociología), indicador do importante grau de integração à rede latino-americana. 
Quadro I ${ }^{12}$

Livros publicados por sociólogos na América Latina ${ }^{\mathrm{I} 3}$

* Universidad Nacional Autónoma de México

\begin{tabular}{|c|c|c|c|c|}
\hline Autor & Título & Editora $^{14}$ & $\begin{array}{l}\text { País/cidade de } \\
\text { publicação }\end{array}$ & Ano \\
\hline \multirow[t]{9}{*}{$\begin{array}{l}\text { José Medina } \\
\text { Echavarría }\end{array}$} & $\begin{array}{l}\text { Panorama de la sociología } \\
\text { contemporânea }\end{array}$ & $\begin{array}{l}\text { La Casa de España en } \\
\text { México }\end{array}$ & México DF & I940 \\
\hline & Sociología. Teoría y Técnica & $\begin{array}{l}\text { Fondo de Cultura } \\
\text { Económica }\end{array}$ & México DF & I94I \\
\hline & Responsabilidad de la inteligencia & $\begin{array}{l}\text { Fondo de Cultura } \\
\text { Económica }\end{array}$ & México DF & I943 \\
\hline & $\begin{array}{l}\text { Presentaciones y planteos. } \\
\text { Papeles de sociología }\end{array}$ & $\begin{array}{l}\text { UNAM* / Instituto de } \\
\text { Investigaciones Sociales }\end{array}$ & México DF & I953 \\
\hline & $\begin{array}{l}\text { Aspectos sociales del desarrollo } \\
\text { económico }\end{array}$ & Andrés Bello & Chile/Santiago de Chile & I959 \\
\hline & $\begin{array}{l}\text { Consideraciones sociológicas sobre } \\
\text { el desarrollo económico }\end{array}$ & Solar/Hachette & Argentina/Buenos Aires & I963 \\
\hline & $\begin{array}{l}\text { El desarrollo social de América } \\
\text { latina en la posguerra }\end{array}$ & Solar/Hachette & Argentina/Buenos Aires & I964 \\
\hline & $\begin{array}{l}\text { Consideraciones sociológicas sobre } \\
\text { el desarrollo económico }\end{array}$ & $\begin{array}{l}\text { Ediciones de la Banda } \\
\text { Oriental }\end{array}$ & Uruguay/Montevideo & 1964 \\
\hline & Filosofía, educación y desarrollo & Siglo XXI & México DF & I967 \\
\hline \multirow[t]{2}{*}{ Gino Germani } & La sociología científica & $\begin{array}{l}\text { UNAM / Instituto de } \\
\text { Investigaciones Sociales }\end{array}$ & México DF & 1956 \\
\hline & Politica e masa & $\begin{array}{l}\text { Revista Brasileira de } \\
\text { Estudos Políticos }\end{array}$ & Brasil/Minas Gerais & I96o \\
\hline \multirow[t]{7}{*}{$\begin{array}{l}\text { Luiz de Aguiar } \\
\text { Costa Pinto }\end{array}$} & $\begin{array}{l}\text { La sociología del cambio y el } \\
\text { cambio de la sociología }\end{array}$ & EUDEBA & Argentina/Buenos Aires & 1963 \\
\hline & $\begin{array}{l}\text { Estructura de clases y cambio } \\
\text { social }\end{array}$ & Paidós & Argentina/Buenos Aires & I964 \\
\hline & $\begin{array}{l}\text { Desarrollo económico y transición } \\
\text { social }\end{array}$ & Revista de Occidente & España/Madrid & I969 \\
\hline & Nacionalismo y militarismo & Siglo XXI & México DF & 1969 \\
\hline & $\begin{array}{l}\text { Estudios de sociología del } \\
\text { desarrollo }\end{array}$ & $\begin{array}{l}\text { Universidad } \\
\text { de Antioquia }\end{array}$ & Colombia/Medellín & I970 \\
\hline & Transición social en Colombia & Universidad Nacional & Colombia/Bogotá & I970 \\
\hline & Voto y cambio & Tercer Mondo & Colombia/Bogotá & I97 I \\
\hline \multirow[t]{7}{*}{ Aldo Solari } & $\begin{array}{l}\text { Las ciencias sociales en el } \\
\text { Uruguay }\end{array}$ & Clapcs & Brasil/Rio de Janeiro & I959 \\
\hline & Sociología rural latinoamericana & EUDEBA & Argentina/Buenos Aires & 1963 \\
\hline & $\begin{array}{l}\text { Elites y desarrollo en América } \\
\text { latina }\end{array}$ & Paidós & Argentina/Buenos Aires & I967 \\
\hline & $\begin{array}{l}\text { Educación, recursos humanos y } \\
\text { desarrollo en América latina }\end{array}$ & Cepal & Chile/Santiago de Chile & I968 \\
\hline & $\begin{array}{l}\text { El cambio social y la política } \\
\text { de desarrollo social en América } \\
\text { Latina }\end{array}$ & Cepal & Chile/Santiago de Chile & 1969 \\
\hline & $\begin{array}{l}\text { Algunas reflexiones sobre la } \\
\text { juventud latinoamericana }\end{array}$ & Ilpes & Chile/Santiago de Chile & I97 I \\
\hline & $\begin{array}{l}\text { Problemas del desarrollo social de } \\
\text { América Latina }\end{array}$ & Ilpes & Chile/Santiago de Chile & I974 \\
\hline \multirow[t]{3}{*}{$\begin{array}{l}\text { Orlando Fals } \\
\text { Borda }\end{array}$} & $\begin{array}{l}\text { Las revoluciones inconclusas en } \\
\text { América latina: (1809-1968) }\end{array}$ & Siglo XXI & México & I968 \\
\hline & $\begin{array}{l}\text { Ciencia propia y colonialismo } \\
\text { intelectual }\end{array}$ & Nuestro Tiempo & México & I970 \\
\hline & $\begin{array}{l}\text { El reformismo por dentro en } \\
\text { América Latina }\end{array}$ & Siglo XXI & México & I972 \\
\hline
\end{tabular}


De qualquer modo, a informação do quadro se torna ainda mais significativa quando se percebe o contraste, em termos de circulação, entre Florestan Fernandes e seu conterrâneo, Luiz de Aguiar Costa Pinto. Enquanto este último publicou, entre I963 e I97 I, sete livros no mercado hispanofalante (dois em Buenos Aires, um no México, três na Colômbia e um na Espanha), o primeiro livro que Florestan Fernandes publicou fora do Brasil, e em língua espanhola, apareceu posteriormente a esse período, mais precisamente em I978, no México, com La revolución burguesa en Brasil (Siglo XXI). ${ }^{15}$

\section{A CIRCULAÇÃo dE FLORESTAN FERNANDES E DE SEUS PRODUTOS}

A fim de mapear a produção e a circulação internacional de Florestan Fernandes, concentramos nossos esforços na localização de três tipos de materiais: os artigos que o autor publicou em revistas estrangeiras, isto é, editadas fora do Brasil; sua participação em eventos científicos internacionais - aqui, incluindo os ocorridos no Brasil -, e as resenhas sobre suas obras que saíram em revistas estrangeiras. ${ }^{16}$ À parte as dificuldades envolvidas neste levantamento, reputamos que ele permite detectar não só a geografia de sua circulação, confrontando-a com a trajetória modal identificada na seção anterior, mas também revelar quais materiais de Fernandes despertaram maior interesse fora do Brasil.

A curva que descreve a cronologia da produção intelectual de Florestan Fernandes nos mostra claramente que, no início de sua trajetória profissional, ele não esteve muito aberto à circulação internacional. Nas linhas que descrevem a evolução temporal dos três materiais aqui levantados - artigos, eventos internacionais e resenhas -, percebemos que há dois "picos" principais, isto é, que concentram as três linhas: os períodos I964-I968 e I969-I97I. Esses dois períodos coincidem com sua maior mobilidade internacional: no primeiro, logo após o golpe militar, Fernandes passa uma temporada em Nova York, na Columbia University, o que também lhe dá a oportunidade de circular por distintas instituições norte-americanas; no segundo, além da publicação da edição condensada em inglês (em volume único) dos dois tomos de A integração do negro na sociedade de classes, em I969, dá-se sua estada como professor no departamento de sociologia da University of Toronto. De modo menos marcado, há um período anterior a esses dois picos, entre i959 e I963, em que Fernandes se conecta, embora não muito intensamente, aos eventos das redes latino-americanas e internacionais da sociologia; e um período posterior, de meados para finais da década de I970, quando ele atua como professor visitante na Yale University e publica, já em I98I, seu segundo livro em inglês, Reflections on the Brazilian counter-revolution (I98I). ${ }^{\text {I7 }}$ 


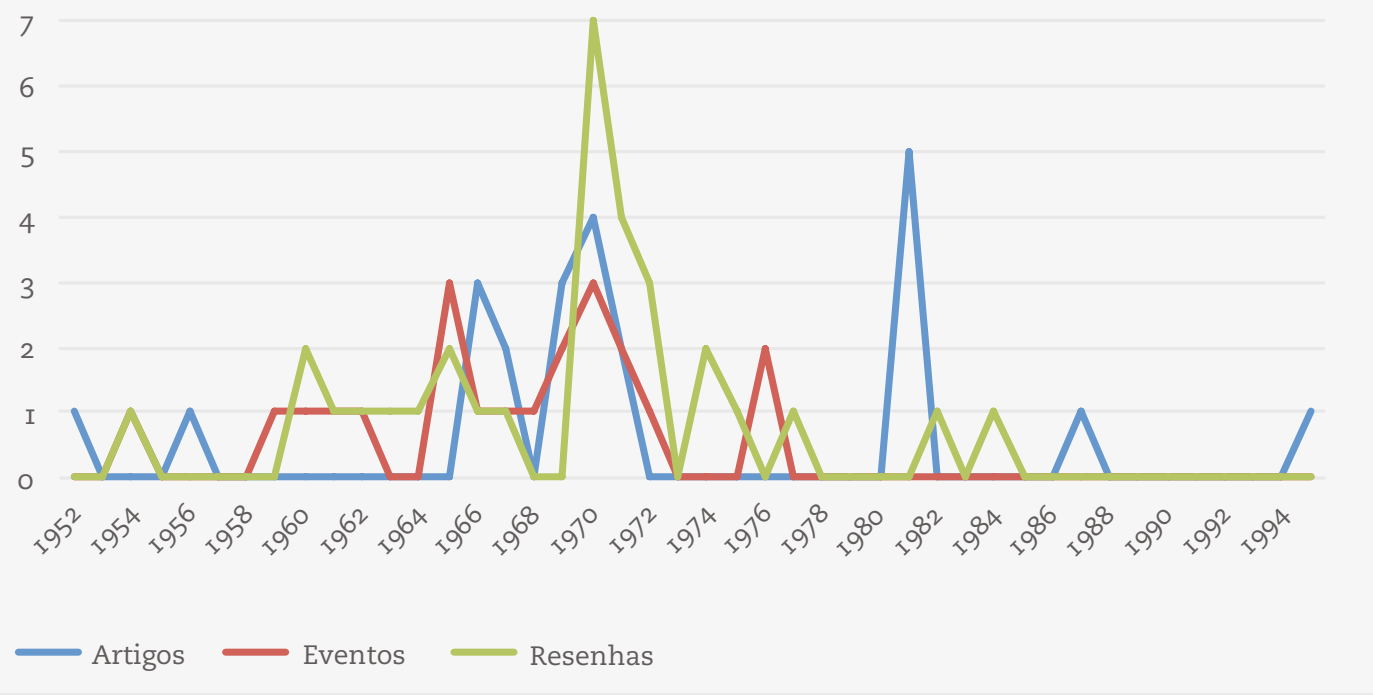

\section{Gráfico I}

Cronologia e quantidade dos artigos e da participação em eventos internacionais de Florestan Fernandes e das resenhas publicadas sobre sua obra

Com efeito, observando-se a publicação de seus artigos no exterior, depois da publicação de dois artigos na década de I950, um na França - no Journal de la Societé des Americanistes, que traduziu para o francês parte de sua tese de doutorado - e outro na Alemanha - na revista Sociologus, com a tradução de Anatol Rosenfeld do artigo "O desenvolvimento histórico-social da sociologia no Brasil” -, em I952 e em I956, respectivamente, passarão dez anos até que o autor volte a publicar em revistas estrangeiras. A partir de então (meados da década de I960), porém, sua produção experimenta um processo de crescente internacionalização. No quadro 2, identificamos, de acordo com as fontes disponíveis, todos os 23 artigos publicados pelo autor no exterior:

\section{Quadro 2}

Artigos publicados por Florestan Fernandes em revistas estrangeiras 


\begin{tabular}{|c|c|c|}
\hline Referência completa do artigo & Ano & País \\
\hline $\begin{array}{l}\text { La guerre et le sacrifice humain chez les Tupinamba } \\
\text { Journal de la Société des Américanistes, 4I/I, p. I39-220 }\end{array}$ & I952 & França \\
\hline $\begin{array}{l}\text { Die Sozialgeschichtliche Entwicklung Der Soziologie in Brasilien } \\
\text { Sociologus, 6/2, p. I0o-I I5 }\end{array}$ & I956 & Alemanha \\
\hline $\begin{array}{l}\text { Las ciencias sociales en Latinoamérica } \\
\text { Revista Mexicana de Sociología, 28/2, p. 251-289 }\end{array}$ & I966 & México \\
\hline $\begin{array}{l}\text { Aspectos da questão racial } \\
\text { O tempo e modo, nov.-dez. }\end{array}$ & I966 & Portugal \\
\hline $\begin{array}{l}\text { La persistencia del pasado } \\
\text { Revista Mexicana de Sociología, 28/4, p. 787-8I I }\end{array}$ & I966 & México \\
\hline $\begin{array}{l}\text { The weight of the past } \\
\text { Daedalus, } 96 / 2 \text {, p. } 560-579\end{array}$ & I967 & Estados Unidos \\
\hline $\begin{array}{l}\text { Immigration and race relations in São Paulo } \\
\text { Présence Africaine, Nouvelle Série, 6I, p. I03-I } 20\end{array}$ & I967 & França \\
\hline $\begin{array}{l}\text { Beyond poverty: the Negro and the Mulatto in Brazil } \\
\text { Journal de la Société des Américanistes, 58, p. I 2 I-I37 }\end{array}$ & I969 & França \\
\hline $\begin{array}{l}\text { El drama del negro y del mulato en una sociedad que cambia } \\
\text { Mundo Nuevo, 33, p. I I-2 I }\end{array}$ & I969 & França \\
\hline $\begin{array}{l}\text { Los dilemas de la reforma consentida } \\
\text { Revista Paraguaya de Sociología, 6/ı6, p. 32-62 }\end{array}$ & I969 & Paraguai \\
\hline $\begin{array}{l}\text { Patrones de dominación externa en América Latina } \\
\text { Revista Mexicana de Sociología, 32/6, p. I439-I459 }\end{array}$ & I970 & México \\
\hline $\begin{array}{l}\text { Os dilemas da reforma universitária consentida } \\
\text { Revista Mexicana de Sociología, 32/4, p. 967-1004 }\end{array}$ & I970 & México \\
\hline $\begin{array}{l}\text { Universidad y desarrollo } \\
\text { Aportes, I7, p. I33-I58 }\end{array}$ & I970 & França \\
\hline $\begin{array}{l}\text { Las pautas de la dominación externa en América Latina } \\
\text { Revista Paraguaya de Sociología, 7/I9, p. 89-103 }\end{array}$ & I970 & Paraguai \\
\hline $\begin{array}{l}\text { Más allá de la pobreza: el negro y el mulato en Brasil } \\
\text { Revista Mexicana de Sociología, 33/2, p. } 253-269\end{array}$ & I97I & México \\
\hline $\begin{array}{l}\text { Rassenbeziehungen in Brasilien: Mythos und Wirklichkeit } \\
\text { Brasilien heute, Frankfurt/M, p. 84-I05 }\end{array}$ & I97I & Alemanha \\
\hline $\begin{array}{l}\text { The autocratic bourgeois model of capitalist transformation } \\
\text { International Journal of Sociology, I I/I-2, p. 5I-I } 25\end{array}$ & I98I & Estados Unidos \\
\hline $\begin{array}{l}\text { Bibliography: selected writings of Florestan Fernandes } \\
\text { International Journal of Sociology, I I/I-2, p. I83-185 }\end{array}$ & I98I & Estados Unidos \\
\hline $\begin{array}{l}\text { The lost generation } \\
\text { International Journal of Sociology, I I/I-2, p. I43-I } 82\end{array}$ & I98I & Estados Unidos \\
\hline $\begin{array}{l}\text { On the formation and development of the competitive social order } \\
\text { International Journal of Sociology, I I/I-2, p. 3-50 }\end{array}$ & I98I & Estados Unidos \\
\hline $\begin{array}{l}\text { Revolution or counter-revolution? } \\
\text { International Journal of Sociology, I I/ I-2, p. I 26-I42 }\end{array}$ & I98I & Estados Unidos \\
\hline $\begin{array}{l}\text { Reform and revolution } \\
\text { Canadian Journal of Latin American and Caribbean Studies, I2/23, p. I5-28 }\end{array}$ & I987 & Canadá \\
\hline $\begin{array}{l}\text { O historiador enquanto jovem } \\
\text { Luso-Brazilian Review, 32/2, p. } 89-92\end{array}$ & I995 & Estados Unidos \\
\hline
\end{tabular}


Analisando essa produção internacional em artigos, podemos observar algumas tendências. Em termos da geografia de sua circulação, dos 23 artigos, sete foram publicados nos Estados Unidos, cinco no México, cinco na França, dois no Paraguai, dois na Alemanha, um no Canadá e um em Portugal, ou seja, ele publica com mais frequência em revistas norte-americanas e europeias, o que também se mostra consistente com as traduções de seus livros no exterior, uma vez que dois deles foram vertidos para o inglês, The negro in Brazilian society (I969) e Reflections on the Brazilian counter-revolution (I98I), e um para o alemão, em dois volumes, Die Integration des Negers in die Klassengesellschaft ${ }^{18}$ (I969, I977). Em espanhol, saiu apenas a edição mexicana de La revolución burguesa en Brasil (I978), ${ }^{19}$ pela Siglo XXI, a editora mexicana que, àquela altura, liderava o mercado do livro de ciências sociais da América Latina. ${ }^{20}$ Ainda no que se refere aos artigos, o salto das publicações nos Estados Unidos no começo da década de 1980 se deve precisamente à publicação de seu segundo livro em inglês - que reuniu os artigos publicados ao mesmo tempo no International Journal of Sociology -, promovido por Warren Dean, autor de um livro clássico sobre a industrialização de São Paulo.

Do ponto de vista dos temas, vemos uma forte presença da questão racial nesses artigos - o que também se revela consistente com a escolha dos livros traduzidos para o inglês e o alemão -, além da incorporação progressiva, a partir de meados dos anos I960, de um enfoque mais regional dos problemas, colocando-se em sintonia com a "regionalização" e com a "latino-americanização" que experimenta a disciplina desde finais da década de I950 (Blanco, 2009; Blanco \& Sorá, no prelo; Brasil Jr., 2013; Bringel et al. 2015).

Outro material que nos ajuda a visualizar a circulação internacional de Fernandes diz respeito a sua participação em congressos e seminários internacionais. De acordo com as fontes disponíveis, compilamos o quadro 3:

\author{
Quadro 3 \\ Trabalhos apresentados por Florestan Fernandes \\ em eventos científicos internacionais \\ * International Congress of Americanists \\ ** Asociación Latinoamericana de Sociología \\ *** International Sociological Association
}




\begin{tabular}{|c|c|c|c|c|}
\hline Seminário & Trabalho apresentado & Ano & Local & Patrocínio \\
\hline XXXI Congresso Internacional de Americanistas & $\begin{array}{l}\text { Caracteres rurais e } \\
\text { urbanos na formação } \\
\text { e desenvolvimento da } \\
\text { cidade de São Paulo }\end{array}$ & I954 & São Paulo & ICA $^{*}$ \\
\hline Resistências à Mudança & $\begin{array}{l}\text { Atitudes e motivações } \\
\text { desfavoráveis ao } \\
\text { desenvolvimento }\end{array}$ & I959 & Rio de Janeiro & Clapcs \\
\hline $\begin{array}{l}\text { Seminário sobre Aspectos Sociais do } \\
\text { Desenvolvimento Econômico na América Latina }\end{array}$ & $\begin{array}{l}\text { Padrão e ritmo de } \\
\text { desenvolvimento na } \\
\text { América Latina }\end{array}$ & 1960 & $\begin{array}{l}\text { Cidade do } \\
\text { México }\end{array}$ & Unesco \\
\hline VI Congresso Latino-Americano de Sociologia & $\begin{array}{l}\text { Possibilidades } \\
\text { e limitações da } \\
\text { investigação sociológica } \\
\text { na América Latina }\end{array}$ & I96I & Caracas & $\mathrm{ALAS}^{* *}$ \\
\hline V Congresso Mundial de Sociologia & $\begin{array}{l}\text { A comunicação entre } \\
\text { o sociólogo e o grande } \\
\text { público }\end{array}$ & I962 & Washington & ISA $^{* * *}$ \\
\hline $\begin{array}{l}\text { The Conference on Race and Class in Latin } \\
\text { America during the National Period }\end{array}$ & $\begin{array}{l}\text { Imigração e relações } \\
\text { raciais }\end{array}$ & 1965 & Nova York & $\begin{array}{l}\text { Cornell University; } \\
\text { Columbia University }\end{array}$ \\
\hline Conferência sobre Estudos Latino-Americanos & $\begin{array}{l}\text { As ciências sociais na } \\
\text { América Latina }\end{array}$ & 1965 & Rio de Janeiro & Clapcs \\
\hline $\begin{array}{l}\text { Conferência do Departamento de Relações } \\
\text { Sociais }\end{array}$ & $\begin{array}{l}\text { A dinâmica da mudança } \\
\text { sociocultural no Brasil }\end{array}$ & 1965 & $\begin{array}{l}\text { Cambridge, } \\
\text { Mass. }\end{array}$ & Harvard University \\
\hline $\begin{array}{l}\text { VI Colóquio Internacional de Estudos Luso- } \\
\text { Brasileiros }\end{array}$ & $\begin{array}{l}\text { Crescimento econômico } \\
\text { e instabilidade política } \\
\text { no Brasil }\end{array}$ & I966 & $\begin{array}{l}\text { Cambridge, } \\
\text { Mass. }\end{array}$ & Harvard University \\
\hline $\begin{array}{l}\text { Segundo Colóquio Científico Ultramarino das } \\
\text { Universidades e Escolas Superiores da Alemanha } \\
\text { Ocidental ("Problemas das sociedades em } \\
\text { desenvolvimento industrial”) }\end{array}$ & $\begin{array}{l}\text { Sociedade de classes e } \\
\text { subdesenvolvimento }\end{array}$ & I967 & Münster & Universität Münster \\
\hline Conference on Race and Color & A persistência do passado & I968 & Copenhagen & $\begin{array}{l}\text { The American Academy } \\
\text { of Arts and Science; The } \\
\text { Congress of Cultural } \\
\text { Freedom }\end{array}$ \\
\hline $\begin{array}{l}\text { Minorias na América Latina e nos Estados } \\
\text { Unidos }\end{array}$ & $\begin{array}{l}\text { Além da pobreza: o negro } \\
\text { e o mulato no Brasil }\end{array}$ & 1969 & Nova York & $\begin{array}{l}\text { The College of the } \\
\text { Finger Lakes }\end{array}$ \\
\hline $\begin{array}{l}\text { Workshop da School of Graduate Studies da } \\
\text { Universidade de Toronto }\end{array}$ & $\begin{array}{l}\text { Sociólogos: os novos } \\
\text { mandarins? }\end{array}$ & 1969 & Toronto & University of Toronto \\
\hline Conferência na Universidade de Toronto & $\begin{array}{l}\text { A ditadura militar e os } \\
\text { papéis políticos dos } \\
\text { intelectuais na América } \\
\text { Latina }\end{array}$ & I970 & Toronto & University of Toronto \\
\hline Conferência na Universidade de Toronto & $\begin{array}{l}\text { Padrões de dominação } \\
\text { externa na América } \\
\text { Latina }\end{array}$ & I970 & Toronto & University of Toronto \\
\hline IX Congreso Latinoamericano de Sociología & $\begin{array}{l}\text { Os dilemas da reforma } \\
\text { universitária consentida }\end{array}$ & 1970 & México, DF & ALAS \\
\hline $\begin{array}{l}\text { A natureza do fascismo e a relevância do } \\
\text { conceito de ciência política contemporânea } \\
\text { (mesa-redonda) }\end{array}$ & $\begin{array}{l}\text { Notas sobre o fascismo } \\
\text { na América Latina }\end{array}$ & I97I & $\begin{array}{l}\text { Cambridge, } \\
\text { Mass. }\end{array}$ & Harvard University \\
\hline $\begin{array}{l}\text { Seminário sobre classes sociais na América } \\
\text { Latina }\end{array}$ & $\begin{array}{l}\text { Classes sociais na } \\
\text { América Latina }\end{array}$ & I97I & Mérida & $\begin{array}{l}\text { U. N. Autónoma de } \\
\text { México }\end{array}$ \\
\hline X Congresso Latino-Americano de Sociologia & $\begin{array}{l}\text { Sociologia, modernização } \\
\text { autônoma e revolução } \\
\text { social }\end{array}$ & 1972 & $\begin{array}{l}\text { Santiago de } \\
\text { Chile }\end{array}$ & ALAS \\
\hline Debate sobre A revolução burguesa no Brasil & $\begin{array}{l}\text { Um ensaio de } \\
\text { interpretação sociológica }\end{array}$ & I976 & Austin & Texas University \\
\hline $\begin{array}{l}\text { Perspectivas comparadas sobre a escravidão nas } \\
\text { sociedades de plantação do Novo Mundo }\end{array}$ & $\begin{array}{l}\text { A sociedade escravista } \\
\text { no Brasil }\end{array}$ & I976 & Nova York & $\begin{array}{l}\text { New York Academy of } \\
\text { Sciences }\end{array}$ \\
\hline
\end{tabular}


Em relação à sua participação em eventos científicos internacionais, observamos que, do total de 2 I eventos, realizados entre i954 e I976, mais de dois terços ocorreram em cidades do hemisfério norte e foram organizados em sua maioria por universidades norte-americanas; e menos de um terço desses seminários foi organizado por organismos regionais de pesquisa em ciências sociais, como o Clapcs, ou associações profissionais, como a Alas.

Por fim, também localizamos as resenhas de livros de Florestan Fernandes publicadas em revistas estrangeiras. Esse material pode revelar, de outra perspectiva, o impacto e a circulação de sua produção fora do Brasil. Mediante consulta às bases de indexação de periódicos e aos materiais disponíveis, chegamos ao quadro 4 (página seguinte).

Do total de 3I resenhas de livros de Fernandes publicadas no exterior nos 30 anos compreendidos entre I954 e I984, apenas três apareceram em revistas do hemisfério sul, uma delas na Revista Latinoamericana de Sociolgía, e assinada por um aluno do autor, Gabriel Cohn, e as outras duas na América Latina, e também nesses casos os dois resenhistas são brasileiros, Roque de Barros Laraia e Manuel Diégues Júnior. As 28 resenhas restantes foram publicadas em revistas reconhecidas de sociologia e das ciências sociais, em sua maioria dos Estados Unidos, como American Sociological Review, Sociology and Social Research, American Anthropologist e em importantes revistas acadêmicas, norte-americanas ou britânicas, especializadas na América Latina, como The Hispanic American Historical Review, Journal of Latin American Studies e The Americas.

Chama a atenção o fato de que, do conjunto das resenhas, I6 (um pouco mais da metade) sejam dedicadas a A integração do negro na sociedade de classes em suas várias edições, em português, inglês e alemão. O que discrepa da menor atenção recebida por Reflections on the Brazilian counter-revolution (I98I) e A revolução burguesa no Brasil (I975), com duas resenhas cada - embora, cabe lembrar, A revolução burguesa no Brasil também tenha sido tema de seminário nos Estados Unidos.

\section{Quadro 4}

Resenhas de livros de Florestan Fernandes em revistas estrangeiras ${ }^{21}$ 


\begin{tabular}{|c|c|c|c|c|}
\hline Resenhista & Livro resenhado & Revista & País & Ano \\
\hline Robert C. Williamson & $\begin{array}{l}\text { Ensaio sobre o método de } \\
\text { interpretação funcionalista na } \\
\text { sociologia }\end{array}$ & Sociology \& Social Research & EUA & I954 \\
\hline Harry W. Hutchinson & $\begin{array}{l}\text { A etnologia e a sociologia no } \\
\text { Brasil }\end{array}$ & The Hispanic American Historical Review & EUA & I960 \\
\hline Raymond S. Sayers & $\begin{array}{l}\text { O padrão de trabalho científico } \\
\text { dos sociólogos brasileiros }\end{array}$ & Revista Hispánica Moderna & EUA & I96o \\
\hline Roger Bastide & Mudanças sociais no Brasil & L’Année Sociologique (I940/ı948-) & FRA & I96I \\
\hline J. V. D. Saunders & Mudanças sociais no Brasil & The Hispanic American Historical Review & EUA & 1962 \\
\hline Roger Bastide & $\begin{array}{l}\text { Folclore e mudança social na } \\
\text { cidade de São Paulo }\end{array}$ & L’Année Sociologique (I940/I948-) & FRA & 1963 \\
\hline Roque de Barros Laraia & $\begin{array}{l}\text { A organização social dos } \\
\text { Tupinambá }\end{array}$ & América Latina & BRA & I964 \\
\hline Manuel Diégues Júnior & $\begin{array}{l}\text { A integração do negro na } \\
\text { sociedade de classes }\end{array}$ & América Latina & BRA & I965 \\
\hline Roger Bastide & $\begin{array}{l}\text { A integração do negro na } \\
\text { sociedade de classes }\end{array}$ & L’Année Sociologique (I940/ı948-) & FRA & 1965 \\
\hline Gabriel Cohn & $\begin{array}{l}\text { A integração do negro na } \\
\text { sociedade de classes }\end{array}$ & Revista Latinoamericana de Sociología & ARG & I966 \\
\hline Lawrence Nevins & $\begin{array}{l}\text { A integração do negro na } \\
\text { sociedade de classes }\end{array}$ & The Hispanic American Historical Review & EUA & I967 \\
\hline Norman E. Whitten, Jr. & The negro in Brazilian society & American Anthropologist & EUA & I970 \\
\hline Evelyn Ina Montgomery & The negro in Brazilian society & American Sociological Review & EUA & I970 \\
\hline William Petersen & The negro in Brazilian society & $\begin{array}{l}\text { The Annals of the American Academy of } \\
\text { Political and Social Science }\end{array}$ & EUA & I970 \\
\hline Anani Dzidzienyo & The negro in Brazilian society & Race & EUA & I970 \\
\hline Parke Renshaw & The negro in Brazilian society & The Hispanic American Historical Review & EUA & I970 \\
\hline F. Henriques & The negro in Brazilian society & International Affairs & ING & I970 \\
\hline José Manuel Roio & $\begin{array}{l}\text { Sociedade de classes e } \\
\text { subdesenvolvimento }\end{array}$ & Análise Social & POR & I970 \\
\hline Egil Fossum & The negro in Brazilian society & Acta sociológica & * & I97 I \\
\hline Michael Banton & The negro in Brazilian society & Sociology & ING & I97 I \\
\hline Philip Mason & The negro in Brazilian society & Jewish Journal of Sociology & ING & I97 I \\
\hline K. B. & $\begin{array}{l}\text { Die Integration des Negers in } \\
\text { die Klassengesellschaft }\end{array}$ & Politische Vierteljahresschrift & ALE & I97 I \\
\hline Robert Conrad & The negro in Brazilian society & The Americas & EUA & I972 \\
\hline Roy A. Glasgow & The negro in Brazilian society & Political Science Quarterly & EUA & I972 \\
\hline Marialice Foracchi & Educação e sociedade no Brasil & International Review of Education & $*$ & I972 \\
\hline Robert M. Levine & $\begin{array}{l}\text { Comunidade e sociedade no } \\
\text { Brasil }\end{array}$ & The Hispanic American Historical Review & EUA & I974 \\
\hline Herbert Minnich & $\begin{array}{l}\text { Comunidade e sociedade no } \\
\text { Brasil }\end{array}$ & Luso-Brazilian Review & EUA & I974 \\
\hline Jordan M. Young & A revolução burguesa no Brasil & The Hispanic American Historical Review & EUA & I975 \\
\hline Carlos Guilherme Mota & A revolução burguesa no Brasil & Luso-Brazilian Review & EUA & I977 \\
\hline Robert M. Levine & $\begin{array}{l}\text { Reflections on the Brazilian } \\
\text { counter-revolution }\end{array}$ & The Hispanic American Historical Review & EUA & 1982 \\
\hline Paul Cammack & $\begin{array}{l}\text { Reflections on the Brazilian } \\
\text { counter-revolution }\end{array}$ & Journal of Latin American Studies & ING & I984 \\
\hline
\end{tabular}




\section{Gráfico 2}

Concentração geográfica (por país) dos artigos e da participação em eventos internacionais de Florestan Fernandes e das resenhas publicadas sobre sua obra

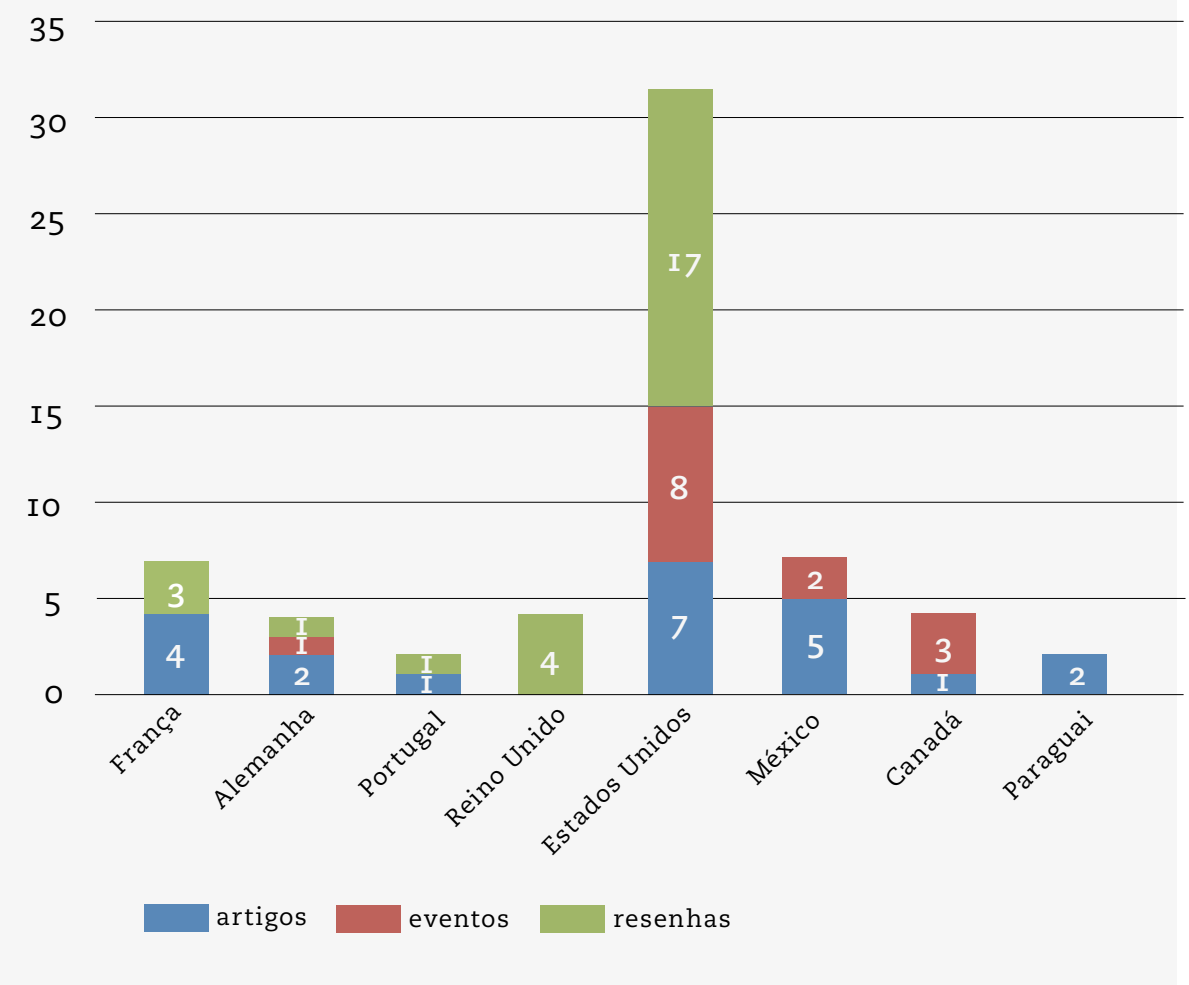

Focalizando apenas a circulação de Florestan Fernandes na América Latina, mediante os dados apresentados, ela pode ser considerada relativamente tardia, caso comparada com a trajetória modal de seus contemporâneos, apresentada na seção anterior. Isso pode ser visualizado de modo apenas indicativo - dadas as limitações da ferramenta Google $\mathrm{Ngram}^{22}$ - na quantidade de referências a seu nome no corpus "Spanish" do Google Books entre I940 e I980, quando confrontado com os nomes dos outros sociólogos mencionados neste trabalho. Vejamos o gráfico na página seguinte.

A curva que descreve as menções ao termo "Florestan Fernandes" no corpus "Spanish" do Google Books mostra-se consistente com os dados anteriormente apresentados. Ela cresce lentamente a partir de I960, chega ao ápice por volta de 1970 e depois se mantém relativamente estável até o final da década. É claro que publicar preferencialmente em português afeta o impacto de Fernandes nas publicações em língua espanhola. Por essa razão, um interes- 


\section{Gráfico 3}

Quantidades de referências aos nomes dos sociólogos

latino-americanos no corpus "Spanish" do Google Books

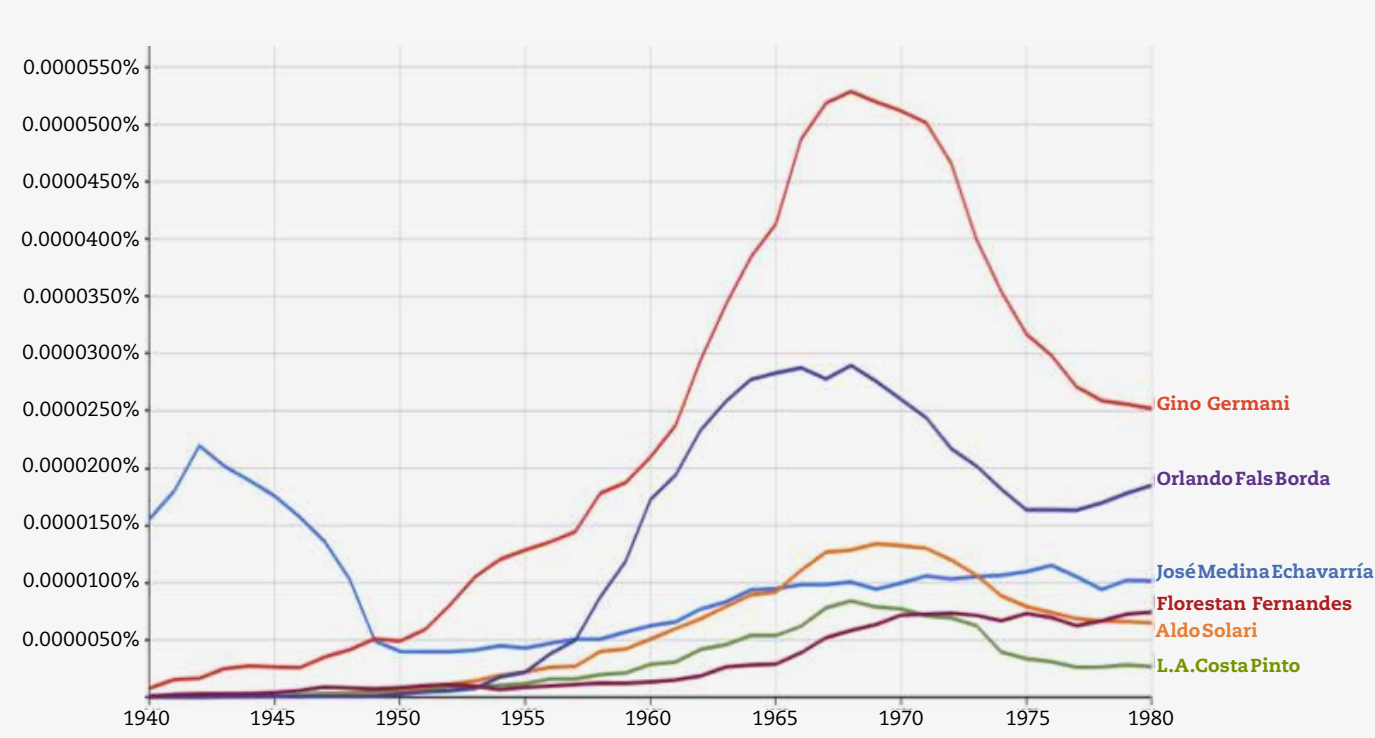

sante caso de controle é o de Luiz de Aguiar Costa Pinto, sociólogo que, ao contrário de Fernandes, esteve diretamente envolvido na criação e dinamização de uma rede latino-americana de sociologia (Bringel et al., 2015; López \& Araújo, 20I I). Entre I955 e I970, Costa Pinto é mais referido que Fernandes nesse corpus textual, situação que só se inverte a partir de I972, o que revela a importância do capital social (capital de relações sociais) na valorização do capital científico detido. Por outro lado, como seria de esperar, as menções a Gino Germani, Orlando Fals Borda, José Medina Echavarría e Aldo Solari, nessa ordem, são consideravelmente maiores que no caso dos sociólogos brasileiros - e, para fins de registro, vale mencionar como Germani e Echavarría se alternam na "liderança" das menções em dois períodos distintos, o último até r 950 e o primeiro entre i950 e i 980 .

Possivelmente a publicação de apenas um livro em espanhol, e mesmo assim tardiamente, pode ter conspirado contra uma circulação mais efetiva da obra de Florestan Fernandes pelo mundo hispanofalante, pois apenas em I 978 foi lançado La revolución burguesa en Brasil, pela Siglo XXI. Também poucos capítulos de livro publicados por Fernandes saíram em espanhol e, de novo, algo tardiamente. Depois de "Posibilidades y limitaciones de la investigación sociológica en la América Latina", disponível nos Anais do VI Congreso Latinoamerica- 
no de Sociología, realizado em I96I, em Caracas, e de "Esquema y ritmo del desarrollo en América latina", em Aspectos sociales del desarrollo económico en América latina, edição preparada por Egbert de Vries e José Medina Echavarría (Unesco, I962), resultado de um seminário no México, em I960, somente em I970 reaparece outro capítulo, "El negro y la revolución burguesa", incluído em América Latina: ensayos de interpretación sociológico-política, em coletânea dirigida por Fernando Henrique Cardoso e Francisco Weffort no Chile (Editorial Universitaria, I970). Um pouco depois, no volume organizado por Raúl Benítez Zenteno, Las clases sociales en América Latina (Siglo XXI, I973), aparece o texto "Problemas de conceptualización de las ciencias sociales en América latina”. Por fim, ainda no México, é publicado "Modelos de dominio externo en América latina", em Anouar Abdel-Malek, Sociología del imperialismo (Instituto de Investigaciones Sociales, I977).

Seja como for, cumpre registrar que o texto "Problemas de conceptualización de las ciencias sociales en América Latina”, apresentado em seminário realizado na cidade de Mérida, no México, em I97 I, recebeu comentário de três reconhecidos sociólogos da região - Rodolfo Stavenhagen, Jorge Graciarena e Jorge Martínez-Rios -, além de figurar ao lado dos textos de Alain Touraine e de Nicos Poulantzas, que igualmente foram comentados por autores especialmente selecionados para tal. Além disso, o livro organizado por Benítez Zenteno, que não só reuniu os textos apresentados, mas também os principais debates do seminário, foi continuamente reeditado de 1973 a I998, quando chega à I I ${ }^{a}$ reedição - o que pode ter favorecido maior circulação da produção de Fernandes na região. Embora organizado pelo Instituto de Investigaciones Sociales da Universidad Nacional Autónoma de México (Unam), a publicação dos anais desse seminário replica o modelo já adotado anteriormente pelo Clapcs, que também incluía nos anais de seus principais eventos os debates presenciais, ao lado das comunicações apresentadas. Em certo sentido, tanto pelos autores escolhidos quanto por sua composição internacional, o seminário de Mérida pode ser comparado a outros eventos patrocinados pelo Clapcs no Rio de Janeiro, como os seminários "Resistências à mudança" (I 959) (Ferreira, I 999), "As ciências sociais na América Latina" (Fernandes, I965) - feito em parceria com o Joint Committe on Latin American Studies, dos Estados Unidos - e "Sociologia do desenvolvimento: aspectos teóricos e metodológicos" (I 968) (Grisendi, 20I4). Se levarmos em consideração que Fernandes foi participante destacado no seminário de 1959 - em que esteve em uma das principais sessões do evento, ao lado de Charles Wright Mills e de Gino Germani - e no de I 965 - para o qual redigiu o informe sobre as ciências sociais na América Latina, além de assinar a orelha da publicação dos Anais do seminário -, vemos que ele esteve presente em alguns dos principais momentos do debate latino-americano da disciplina.

Tomando os dados apresentados em conjunto - artigos, seminários e resenhas -, podemos imputar a relativa concentração geográfica da circulação 
latino-americana de Fernandes no México ao timing de sua circulação regional. México foi o país da América Latina em que o autor publicou cinco de seus 20 artigos no exterior - todos na Revista Mexicana de Sociología -, aos quais se somam apenas os outros dois que saíram na Revista Paraguaya de Sociología. Seu único livro em espanhol e dois dos capítulos publicados em espanhol, como vimos acima, foram publicados no México. Não há dúvidas de que essa circulação concentrada no país asteca esteve condicionada por razões políticas: desde meados da década de I970, as ditaduras do cone sul (especialmente as que se iniciaram em I 973 no Chile e no Uruguai e em I 976 na Argentina, países em que as ciências sociais tinham conhecido desenvolvimento muito expressivo) fecharam os cursos de ciências sociais, provocando o exílio de seus professores, muitos dos quais se radicaram no México, convertendo esse país no anfitrião de muitos cientistas sociais da região. Estando a salvo das ditaduras que afetaram a vida intelectual de vários países do cone sul (incluindo o Brasil), o México contava, ademais, com importante infraestrutura e tradição nas ciências sociais (instituições de ensino, pesquisa, revistas, editoras). Sua condição de país anfitrião para os exilados das ciências sociais latino-americanas o colocou no centro de gravitação do desenvolvimento das ciências sociais latino-americanas. Tudo isso torna compreensível o fato de que essa circulação de Fernandes pela América Latina se tenha concentrado nesses anos quase exclusivamente no México.

\section{HIPÓTESES EXPLICATIVAS}

A circulação internacional dos agentes depende de diversos fatores, sendo ss migrações (voluntárias ou forçadas) um deles. As relações de força desiguais entre países centrais e periféricos, que promovem viagens de treinamento para os centros metropolitanos, constituírem outro. Como explicar a tardia circulação regional/internacional de Florestan Fernandes, em contraste com a trajetória modal de seus contemporâneos? Nossa hipótese afirma que a dita explicação pode ser imputada à combinação de duas condições excepcionais que caracterizam o processo de formação/institucionalização das ciências sociais na cidade de São Paulo.

A primeira delas foi a presença de "missões estrangeiras" contratadas oficialmente para montar os respectivos programas de ensino e pesquisa - com forte acento francês, na Universidade de São Paulo (USP), e norte-americano, na Escola Livre de Sociologia e Política (ELSP) (Peixoto, I989). Nesse sentido, as missões "francesa" e "norte-americana" operaram como uma espécie de substituto funcional das viagens de formação e de aquisição de capital científico internacional, oferecendo às primeiras gerações de cientistas sociais da cidade de São Paulo um milieu internacional de formação intelectual.

Certamente, a presença internacional não foi um traço exclusivo da experiência de institucionalização das ciências sociais em São Paulo. Ainda no caso brasileiro, também foi forte a presença internacional na cidade do Rio de Janeiro, àquela altura capital do país. O curso de ciências sociais da Faculdade 
Nacional de Filosofia da Universidade do Brasil contava com forte presença francesa em seu quadro docente. ${ }^{23} \mathrm{Na}$ Argentina, quando Gino Germani assumiu, na Universidade de Buenos Aires, a liderança institucional e intelectual do curso recém-criado de sociologia, ele mobilizou uma série de estratégias de construção da disciplina que terminaram por convertê-la em uma instituição semelhante a um centro internacional de estudo e de pesquisas. Uma delas foi um intensivo programa de cooperação científica com professores e pesquisadores estrangeiros - europeus, norte-americanos e latino-americanos. No transcurso de poucos anos, vários professores estrangeiros - Alain Touraine, Araon Cicourel, Kalman Silvert, Irving Horowitz, Peter Heintz, Bernard Rosemberg, José Medina Echavarría, Luiz Aguiar de Costa Pinto, Ralph Beals, Albert Meister, Samuel N. Eisenstadt, George Balandier, Fernando Henrique Cardoso, Enzo Faletto, Johan Galtung, Joffre Dumazedier e Paul Baran - realizaram distintas atividades de ensino e pesquisa no Departamento e no Instituto de Sociologia da UBA. Uma estratégia similar foi adotada por Orlando Fals Borda no departamento de sociologia por ele fundado na Universidad Nacional de Bogotá, em I959, com o auxílio dos fundos da Unesco e da Fundação Fullbright (Cataño, I987, 2008; Restrepo Forero, 2002; Jaramillo, 2006, 2010). A presença internacional foi ainda mais dominante em Santiago de Chile, que, na condição de sede da maior parte dos organismos internacionais, incluindo a Flacso, converteu-se no espaço mais transnacional da região. Tampouco no México faltou a variável internacional ou a presença estrangeira. A migração intelectual espanhola de finais da década de I930 teve papel decisivo na construção de algumas instituições acadêmicas e culturais mais importantes, como El Colegio de México e a editora do Fondo de Cultura Económica (FCE). E ainda que o impacto dessa migração intelectual tenha sido mais importante nas humanidades do que nas ciências sociais, as iniciativas de José Medina Echavarría à frente da coleção de sociologia do FCE, bem como do Centro de Estudios Sociales no El Colegio de México, não deixariam de exercer uma renovação na cultura das ciências sociais mexicanas.

O que, no entanto, constituiu exclusividade de São Paulo foi a modalidade da presença estrangeira e sua "composição intelectual", digamos assim. À diferença dos estrangeiros que participaram como experts nos outros países da região, por breves períodos, alguns professores da "missão estrangeira" em São Paulo, tanto na USP quanto na ELSP, permaneceram por um tempo prolongado, como Donald Pierson (I 8 anos), Roger Bastide (I6 anos), Emilio Willems (Io anos), ${ }^{24}$ Herbert Baldus (mais de 20 anos) e Pierre Monbeig (I I anos), o que, por sua vez, permitiu absorção mais eficaz dos novos padrões de trabalho. ${ }^{25}$ Além disso, São Paulo foi a única cidade da América Latina que recebeu, ao mesmo tempo, o impacto prolongado de tradições nacionais das ciências sociais de diferentes origens: francesa, norte-americana e alemã.

Uma segunda condição, de ordem institucional e ainda mais excepcional, caracterizou o processo de institucionalização das ciências sociais em São Pau- 
lo. Desde meados da década de I940, a cidade era a única da América Latina que oferecia formação universitária completa em ciências sociais suficientemente sólida, de perfil acadêmico e articulada - graduação, mestrado e doutorado - e um número significativo de revistas especializadas (Jackson, 2004) em condições de canalizar essa nova produção cultural, o que tornava relativamente desnecessária a "saída" para o exterior (circulação/internacionalização) fosse em busca de formação especializada ${ }^{26}$ ou de locais de publicação.

Com respeito ao primeiro aspecto, a USP oferecia a graduação em ciências sociais, a ELSP o mestrado, e a USP o doutorado - a própria trajetória de Fernandes é a melhor testemunha dessas possibilidades, que ele buscou aproveitar ao máximo. ${ }^{27}$ Nem Chile, nem Argentina, nem México, nem Uruguai es tavam em condição de oferecer formação universitária completa em ciências sociais - mesmo os cursos de graduação em sociologia foram um fenômeno tardio no resto dos países da América Latina. ${ }^{28}$ No México, mais precisamente na Facultad de Ciencias Políticas y Sociales (FCPyS) da Unam, a mais importante do país nesse momento, a criação do primeiro programa de pós-graduação só ocorreu em 1967. ${ }^{29}$ Por essa razão, a maioria dos que formaram até então o plantel docente da FCPyS havia obtido sua formação de pós-graduação no exterior. ${ }^{30} \mathrm{Na}$ Argentina, a formação de pós-graduação em ciências sociais é fenômeno muito recente (Blanco \& Wilkis, no prelo). Na área específica da sociologia, a Facultad de Ciencias Sociales da Universidade de Buenos Aires lançou seu primeiro programa de mestrado em 1995 e, dois anos mais tarde, o de doutorado; o que permite compreender por que a "saída" para o exterior foi tão frequente entre os professores e estudantes dos dois países que contavam com forte tradição intelectual e institucional das ciências sociais, como Argentina e México. Não é causal, portanto, que a maioria dos usuários da Escuela Latinoamericana de Sociología da Flacso tenha sido constituída de graduados universitários desses países, que encontravam na novíssima instituição regional a possibilidade de compensar a ausência de formação especializada em sociologia nos seus respectivos países de origem.

Os efeitos desse diferencial institucional também podem ser vistos com toda nitidez comparando-se as trajetórias de formação dos primeiros alunos dessas lideranças intelectuais da sociologia. Enquanto os sociólogos formados por Gino Germani, Eduardo Hamuy, Orlando Fals Borda e Lucio Mendieta y Núñez foram enviados por seus mestres ao exterior, a fim de obter uma formação especializada (ou de pós-graduação) em sociologia - uma vez que não a poderiam obter no mercado acadêmico doméstico -, os primeiros e mais importantes alunos de Florestan Fernandes, Fernando Henrique Cardoso, Octavio Ianni, Marialice Mencarini Foracchi e Maria Sylvia de Carvalho Franco, realizaram toda a sua formação de graduação e de pós-graduação na Faculdade de Filosofia, Ciências e Letras da USP. E, aliás, suas saídas para o exterior, como no caso também de Fernandes, só ocorreriam depois do golpe de $1964 \cdot{ }^{31}$ 
No que diz respeito aos meios de difusão, desde o início os cientistas sociais paulistas tinham à disposição um relevante número de revistas especializadas - Sociologia [I 939-I964], Revista do Arquivo Municipal [1935], Revista do Museu Paulista [nova série, I947] e Revista de Antropologia [1953], e também, ainda que de perfil menos acadêmico, Anhembi (I950-I962) e Revista Brasiliense (I955-I964) - sem equivalente na região ${ }^{32}$ e cujos mentores eram, na maioria dos casos, os mesmos professores estrangeiros que estavam no comando das instituições de formação. A produção intelectual das duas primeiras gerações de cientistas sociais foi publicada nessas revistas.

A conjunção destas três condições - forte presença internacional, possibilidades de formação completa em ciências sociais e meios especializados de difusão -, o que também se liga à implantação relativamente precoce de cursos de ciências sociais em São Paulo (e no Brasil), explica a "tardia" circulação internacional de Fernandes, bem como a "saída" tardia de seus primeiros discípulos. Se a presença internacional tampouco inexistiu em outros países - Argentina, México, Chile, Uruguai -, a falta de estrutura institucional capaz de oferecer formação completa em ciências sociais promoveu a saída para o exterior e, por conseguinte, a circulação internacional de seus aspirantes. Nesse sentido, as condições nas quais os paulistas desenvolveram sua formação durante esse período de consolidação das ciências sociais universitárias nos obrigam a estabelecer uma distinção entre "circulação internacional" e "internacionalização". Embora "circulação internacional” implique "internacionalização", esta última não implica necessariamente a primeira. Assim, por exemplo, a formação no exterior, que supõe a internacionalização mediante a aquisição de um capital científico internacional, não implica necessariamente a posteriori a circulação internacional desse agente e de seus produtos (ainda que a formação no exterior seja, ela também, uma modalidade de circulação internacional). Fernandes circulou muito menos que seus contemporâneos, certamente, mas não estava menos internacionalizado que eles. ${ }^{33}$ Se a trajetória modal aqui identificada demonstra elevado grau de circulação nas principais lideranças da sociologia na região, isso ocorre porque cada um, a seu modo, enfrentou condições domésticas distintas para responder às pressões de um contexto de internacionalização crescente das ciências sociais e uma nova configuração institucional disposta a retribuir àqueles que detinham formação especializada e internacional de seu capital científico. ${ }^{34}$

\section{CONSIDERAÇÕES FINAIS: A AMÉRICA LATINA POSSÍVEL}

Como vimos até aqui, usando como critérios de circulação internacional a mobilidade acadêmica e a produção científica publicada fora de seu país de origem, Florestan Fernandes certamente circulou menos que seus contemporâneos, especialmente no contexto latino-americano. De acordo com nossas hipóteses - que não pretendem, por óbvio, esgotar a questão -, isso foi condicionado pelas 
especificidades da institucionalização das ciências sociais em São Paulo que, além de sua implantação precoce, em relação às demais cidades da região, tornava possível uma formação acadêmica completa, da graduação ao doutorado, tornando a "saída" para o exterior apenas uma possibilidade, e não uma etapa obrigatória.

Essa configuração viabilizou uma estratégia na qual Fernandes parece ter apostado todas as suas fichas: a criação de um grupo de sociólogos capaz de realizar pesquisas empíricas e inovações teóricas coletivamente, numa agenda compartilhada e de longo prazo. Em entrevista concedida à revista Trans/ form/ação, em I975, ele assinala, retrospectivamente, o teor dessa aposta. Ao suceder a Roger Bastide na regência da cadeira de sociologia I da USP, ele teria conseguido criar condições intelectuais e institucionais para a organização desse grupo, cujo núcleo duro era formado por Fernando Henrique Cardoso e Octavio Ianni, primeiro e segundo assistentes da cadeira, mas também por Maria Sylvia de Carvalho Franco e Marialice M. Foracchi, auxiliares de ensino (e depois, também, assistentes). Com isso, suas ambições teriam sofrido uma "rotação completa", pois, em suas palavras, "com esse grupo a ênfase se deslocou da [...] carreira como sociólogo individual, para a constituição de um grupo que deveria produzir sociologia". Com isso, o que mais o preocuparia seria criar "as condições institucionais da produção em grupo" (Fernandes, I978: 22).

Ora, essa aposta no trabalho em equipe não era exclusividade do grupo de Florestan Fernandes, mas algo que era almejado e valorizado pela sociologia "científica" que se difundia no momento, também na América Latina. Aqui, porém, mais uma vez, entram em jogo as especificidades do contexto de São Paulo. Fernandes pôde imprimir uma orientação compartilhada ao seu "grupo" e de modo contínuo durante pelo menos dez anos, de I954 a I964, período em que realizaram juntos as atividades de docência da cadeira de sociologia I, além de atuar coletivamente nas pesquisas sobre as relações raciais no Brasil meridional e na elaboração do projeto "Economia e sociedade no Brasil", que orientaria as atividades no Centro de Sociologia Industrial e do Trabalho (Cesit), órgão anexo à cadeira, criado em I962 (Romão, 2006). Apenas depois do golpe de I964 é que o grupo começa a sofrer desagregação mais acentuada, não só em razão da pressão política - que leva imediatamente à saída de Fernando Henrique Cardoso para Santiago do Chile -, mas também da pressão interna de maior diferenciação intelectual e autonomia em relação às orientações teóricas imprimidas pelo responsável pela cadeira.

Apesar da existência de convites para lecionar em universidades ou centros de pesquisa latino-americanos - resultado da dinamização do mercado de postos para a sociologia, especialmente por meio das iniciativas patrocinadas pela Unesco -, Fernandes decide enfrentar os riscos políticos e permanecer à frente da cadeira de sociologia I da USP, até ser aposentado compulsoriamente em I969. ${ }^{35}$ Embora tenha feito saídas ao exterior nesse período - a mais longa 
para a Columbia University, em Nova York -, continuou atuando fundamentalmente em âmbito local, a fim de manter minimamente as condições de funcionamento de seu "grupo" na USP, a despeito da situação adversa. Representativa dessa estratégia, fruto de seu envolvimento integral com as condições de desenvolvimento da sociologia na USP, é a comunicação "As ciências sociais na América Latina", apresentada no evento de mesmo nome realizado no Rio de Janeiro, pelo Clapcs, em maio de I965. Ali, Fernandes defende a importância do conhecimento sociológico feito nos países latino-americanos e alerta contra os riscos de uma absorção acrítica das orientações intelectuais inscritas nas novas formas de cooperação científica, especialmente nos estudos "latino-americanistas" dos Estados Unidos. ${ }^{36}$ Temeroso com a criação de novas redes de dependência cultural que pudessem colocar em risco a autonomia intelectual de seu "grupo", Fernandes adverte permanentemente Fernando Henrique Cardoso, que estava em sua estada chilena, dos perigos associados à "internacionalização" precoce da carreira, como podemos ver nas cartas que trocaram nesse período. A carta de i I de julho de I964 - escrita, portanto, pouco tempo depois da saída de Cardoso - exprime com notável nitidez a posição de Fernandes sobre esse ponto:

A curta permanência do Nuno [Fidelino de Figueiredo] mostrou-me o lado negativo da carreira em moldes "internacionais". Ela é compensadora, mas demasiado onerosa: desenraiza e desossa a pessoa. [...] Ficar enterrado aqui também é mau. Perdemos perspectiva e, o que é pior, acaipiramos a nossa escala de grandeza - tanto a científica quanto a humana. É claro que o raciocínio não vale para as emergências. Nestes casos, a saída internacional é [a] única viável. Meio de sobrevivência e tábua de salvação. Contudo, para durar o menos possível e ser, em tempo, colocada em termos normais da carreira científica de cada um de nós. / Agora, precisamos de você mais do que nunca. Entre os jovens está batendo um desânimo perigoso. Ir para o estrangeiro, que sempre foi um dos traços do nosso provincialismo intelectual, está se convertendo em ideal de vida. [...] Sempre batalhei para que o pessoal saísse quando pudesse aproveitar a saída. Agora, parece que se fixa uma tendência: o especialista de valor é o que pode sair... Isso é horrível (carta de Florestan Fernandes a Fernando Henrique Cardoso, II/7/I964, Arquivo Instituto FHC).

Como salienta em algumas entrevistas e textos autobiográficos, Fernandes (I977, I978) apostava na lógica do "pequeno grupo", coeso, mas flexível, como forma de se contrapor aos influxos poderosos e concomitantes - e, para ele, associados - do conservadorismo interno e da dependência cultural externa. Contra a "pulverização e a domesticação", o preço a ser pago seria a criação de uma instituição que "tinha de gravitar sobre si mesma", buscando "dentro dos seus muros e de si própria a força para existir, crescer e multiplicar-se" (Fernandes, I977: 220). Era a partir da perspectiva dos avanços acumulados por seu "grupo" na USP que Fernandes avaliava e media a circulação científica internacional, e não o contrário, o que segundo ele era uma forma de contornar "nosso provincialismo cultural" (nos termos da carta acima). Sem dúvida, muito de sua 
energia se consumiu na formação e na manutenção desse grupo - daí seu pessimismo quanto aos rumos da Universidade depois de sua dispersão no pós-I 964.

Talvez essa concentração na construção de um grupo de sociólogos no interior da USP tenha tornado menos crucial sua articulação à emergente rede de pesquisadores latino-americanos que, desde meados dos anos I950, vinha criando espaços de formação e de pesquisa pela região. ${ }^{37}$ Afinal, essa criação de espaços pode ser vista, também, como uma estratégia para contornar as impossibilidades de uma formação completa em ciências sociais na América Latina, o que não acontecia, como vimos, no caso de São Paulo. De todo modo, mesmo que não se engajando diretamente nessas redes latino-americanas, Fernandes e seu "grupo" da USP não deixaram de participar de alguns de seus principais eventos, assumindo até mesmo, em alguns deles, posição de destaque, sobretudo naqueles sediados no Rio de Janeiro. Quer dizer, apesar de menos integrado a essas redes que seus contemporâneos da região, Fernandes não foi indiferente aos seus movimentos, muito pelo contrário. E a proximidade de São Paulo com o Rio de Janeiro, que figurava como um dos hubs da conexão latino-americana (Bringel et al., 20I5; Grisendi, 20I4), certamente facilitou o estabelecimento de vínculos.

Não obstante a existência desses vínculos - mais frouxos que firmes - do "grupo" de Fernandes com a rede de sociólogos latino-americanos na primeira metade dos anos I960, o golpe de I964, pressionando pela dispersão do grupo, implicou uma sorte de "latino-americanização" tardia. Mas é curioso que a aproximação à região - menos um projeto que uma resposta a uma circunstância política - tenha se dado menos diretamente pela rede de sociólogos latino-americanos e mais pelos contatos estrangeiros prévios que já tinham circulado por São Paulo, especialmente Alain Touraine e Charles Wagley. Por intermédio do primeiro, Fernando Henrique Cardoso procurou costurar pesquisas coletivas e comparadas na América Latina, a partir de sua atuação em Santiago de Chile; por intermédio do segundo, Florestan Fernandes teve a oportunidade de passar uma temporada acadêmica em Nova York no Institute of Latin American Studies (Columbia University), preterindo outros convites análogos feitos por instituições latino-americanas.

A título de conclusão, cabe uma breve indicação de como essa modalidade tardia de "circulação internacional" de Florestan Fernandes - o que não significa uma "internacionalização" tardia, como esclarecemos na seção anterior - condicionou sua perspectiva teórica em relação à América Latina, entendida como unidade analítica de teorização sociológica. Como ele mesmo admite em texto autobiográfico, sua estada na University of Toronto, entre I969-1972, obrigou-o "a fazer análises comparadas" e, como resultado, ele teria passado a ver a sociedade brasileira "à luz de processos análogos, que estavam ocorrendo em outros países da América Latina". Ainda de acordo com Fernandes, essas comparações teriam sido decisivas, pois "evidenciavam em que sentido o que acon- 
tecia no Brasil era típico de um 'estágio de incorporação', que exacerbava a dominação burguesa e a levava a converter o Estado autocrático, a um tempo, em uma cidadela e em um santuário" (Fernandes, I 977: 203-204). Forçando um pouco a nota, podemos dizer que Fernandes finalmente incorporou a América Latina não por meio de sua circulação pelos países da região, como fizeram seus contemporâneos - e também Fernando Henrique Cardoso, sobretudo em sua experiência em Santiago de Chile -, mas por meio de sua circulação pela América do Norte. A combinação de uma intensa e prolongada relação com a sua sociedade de origem, como atesta sua vasta produção desde a década de I940 sobre os processos de mudança social no Brasil, com os contatos de "segunda mão" com o restante da América Latina que lhe foram exigidos durante sua atuação no Canadá, acabaram condicionando um tipo de generalização muito própria e original. Fernandes, particularmente em Capitalismo dependente e classes sociais na América Latina (Fernandes, I98I) e em A revolução burguesa no Brasil (Fernandes, 2006), em vez de analisar as variações internas que acompanham os processos de modernização nos vários países da América Latina, prefere tomar o caso brasileiro como heurístico para se pensar o conjunto dos países periféricos do capitalismo.

No seminário de Mérida, em I97 I, essa posição foi criticada por Jorge Graciarena (I973: 298), que, no seu comentário ao texto apresentado por Fernandes, reforça que "as generalizações sobre a região são necessárias e úteis, mas seriam enganosas se, ao mesmo tempo, não tivessem em conta as diferenças nacionais que são muito consideráveis". Além disso, insiste que é fundamental considerar "as transformações temporais nos padrões de dependência e de estratificação social”. Na sua resposta, Fernandes (I973: 4I2) argumenta que a nitidez com que a articulação entre o desenvolvimento do capitalismo e a persistência do subdesenvolvimento transparece no Brasil permitiria apanhar "os aspectos centrais, os processos [que] são fundamentais", mesmo que os países em questão "possam ser diferentes". Como esclarece em outros textos do mesmo período, a sociedade brasileira seria uma espécie de "tipo extremo" do capitalismo dependente, pois nela estariam presentes "tanto os aspectos mais arcaicos quanto os aspectos mais modernos da estratificação social condicionada pelo capitalismo dependente" (Fernandes, I975: 50). Daí que, à maneira de Marx sobre o caso inglês no século XIX, Fernandes tenha se referido ao caso brasileiro num registro equivalente: “o presente do Brasil contém o futuro de outros países, que pertençam à periferia do capitalismo mundial e não possam encaminhar-se diretamente para o socialismo" (Fernandes, 2006: 259).

Do Brasil, pode-se entender a marcha do capitalismo global na região eis a América Latina possível de Florestan Fernandes. 


\begin{abstract}
Alejandro Blanco é mestre em sociologia da cultura pela Universidade Nacional General San Martín e doutor em história pela Universidade de Buenos Aires (UBA), onde também se graduou em sociologia. Atualmente é professor de sociologia na Universidade Nacional de Quilmes, membro do Centro de História Intelectual dessa universidade e pesquisador do Conselho Nacional de Investigações Científicas e Técnicas (Conicet). É autor de Razón y modernidad. Gino Germani y la sociología en la Argentina (2006) e, em coautoria com Luiz Jackson, Sociologia no espelho. Ensaístas, cientistas sociais e críticos literários no Brasil e na Argentina (I930-I970) (2014).
\end{abstract}

Antonio Brasil Jr. é mestre e doutor em sociologia pelo Programa de Pós-Graduação em Sociologia e Antropologia da Universidade Federal do Rio de Janeiro (UFRJ), onde atualmente é professor adjunto do Departamento de Sociologia e do PPGSA. É autor de Passagens para a teoria sociológica (2013). 


\section{NOTAS}

I Agradecemos imensamente a leitura e os comentários feitos pelos pareceristas anônimos de Sociologia \& Antropologia, bem como as sugestões de aperfeiçoamento da proposta aqui apresentada. Para a realização deste artigo, foram consultados os seguintes arquivos: Fundo Florestan Fernandes (Biblioteca Comunitária da Universidade Federal de São Carlos), Arquivo do Instituto Fernando Henrique Cardoso e Arquivo Irving Louis Horowitz-Transaction (Penn State University).

2 Em I965-I966, por intermédio de Charles Wagley, Florestan Fernandes foi professor visitante na Columbia University, em Nova York; em 1969-1972, Fernandes se tornou resident scholar e logo depois full professor na University of Toronto. Não obstante, regressou ao Brasil nos anos I970, lecionando na PUC de São Paulo. Em I977, passou um ano na Yale University, em New Haven, e em I978, quando já havia passado a etapa mais dura da ditadura, regressou ao Brasil como professor full time da PUC de São Paulo.

3 No caso dos estrangeiros, como Gino Germani e José Medina Echavarría, de origem italiana e espanhola, respectivamente, a circulação internacional foi, no começo, efeito de migrações forçadas por conjunturas políticas adversas. Em I930, Germani havia sido preso por atividades antifascistas e condenado a quatro anos de confinamento na ilha de Ponza. Quatro anos mais tarde, estabeleceu-se na Argentina. Medina Echavarría, que havia atuado como membro do governo da República espanhola, exilou-se no México em I939 em consequência da derrota dos republicanos na Guerra Civil Espanhola.

4 José Medina Echavarría formou-se em filosofia e jurisprudência nas universidades de Valência e Madri. Em I926, estabeleceu-se na Universidade de Paris como fellow para completar sua graduação e, entre I930 e I933, depois do doutorado, passou duas temporadas na Alemanha se familiarizando com a tradição sociológica desse país. Graduado em direito na Universidad de la República, Aldo Solari estudou sociologia da educação na London School of Economics and Political Science, na Inglaterra, e no Institut National d'Études Démographiques e na Sorbonne, na França . Orlando Fals Borda estudou literatura inglesa 
na University of Dubuque, Iowa (I944-I947), fez mestrado na University of Minnesota (I952-I953) e doutorado na University of Florida (I954-I957). Pablo González Casanova formou-se em história em El Colegio de México e se doutorou na Université de Paris, sob a orientação de Fernand Braudel.

5 José Medina Echavarría dirigiu a "Colección de Sociología" no Fondo de Cultura Económica, e Gino Germani a de "Psicología Social y Sociología” na Paidós (Blanco, 2006; 2009).

6 Gino Germani foi vice-presidente da ISA entre I962-I966; Luiz de Aguiar Costa Pinto e Aldo Solari integraram o comitê executivo da organização entre I954-1957 e I966I970, e a vice-presidência entre I956-I959 e I970-I974, respectivamente.

7 Dos 247 graduados na Escuela Latinoamericana de Sociología da Flacso entre I957 e I973, 69 eram chilenos, 54 argentinos, 29 brasileiros e 2I mexicanos (Franco, 2007). Uma parcela expressiva dos brasileiros que obtiveram sua pós-graduação na Flacso e que seguiram carreiras acadêmicas provinha da Universidade Federal de Minas Gerais (UFMG), como Antonio Cintra, Fabio Wanderley Reis, Simon Schwartzman, Vilmar Faria e Orlandina de Oliveira. Esse fato não surpreende quando se lembra que a UFMG esteve ativamente envolvida nas negociações em torno da criação da Flacso por intermédio de Orlando Carvalho, que integrou o Comitê Diretor da Flacso e, junto a Francisco Iglesias e Julio Barbosa, foi o mentor dessa nova geração que fundaria a ciência política no Brasil, primeiro em Minas Gerais e mais tarde no Rio de Janeiro. Orlando Carvalho foi o criador e principal animador da Revista Brasileira de Estudos Políticos, que, em I96o, publicou "Política e massa", de Gino Germani.

8 Organizados e/ou auspiciados pelos diferentes organismos internacionais (OEA, Unesco, Cepal) e pelos dois centros regionais de ensino (Flacso) e de pesquisa (Clapcs), dos dez seminários mais importantes celebrados nos dez anos compreendidos entre I958 e I968, três se realizaram em Buenos Aires, três no Rio de Janeiro, dois em Santiago do Chile, um em Montevidéu e um no México.

9 Porém, depois do golpe de 1964, quando Fernando Henrique Cardoso já se encontrava no Chile, podemos ver na 
troca de cartas entre Fernandes e Cardoso uma série de tentativas de concretizar sua ida à Flacso, aliás, com o aval de Peter Heintz, diretor da Escuela Latinoamericana de Sociología (Arquivos do Fundo Florestan Fernandes, da Biblioteca Comunitária da Universidade Federal de São Carlos e do Instituto Fernando Henrique Cardoso).

Io O exame da correspondência de Fernandes com Germani revela que, em um dado momento, essa possibilidade se frustrou por razões relativas à política editorial da revista. Com efeito, em carta dirigida a Fernandes de janeiro de 1965, Germani agradecia ao sociólogo brasileiro o envio de seu trabalho "A dinâmica da mudança sociocultural no Brasil", expressando seu desejo de publicá-lo na revista. Ao que tudo indica, o trabalho não foi publicado provavelmente porque não era inédito, embora não nos seja possível comprovar essa suposição (carta de Gino Germani a Florestan Fernandes, 24/I/I965, Fundo Florestan Fernandes, Biblioteca Comunitária da Universidade Federal de São Carlos). Um ano depois, Irving Louis Horowitz, com quem Fernandes teve contato pessoal durante sua estada em Nova York, lhe solicita o mesmo artigo - e também "Immigration and race relations in São Paulo" - para publicação na Comparative International Development Series, revista editada por ele na Transaction. De modo análogo ao que aconteceu com Germani, porém, esses artigos não vieram a lume (carta de Irving Louis Horowitz a Florestan Fernandes, 20/I/I966, Transaction-Horowitz Archives, Penn State University).

I I Paidós (Gino Germani/diretor de coleção), Fondo de Cultura Económica (José Medina Echavarría/diretor de coleção), EUDEBA (Gino Germani/indireto), Revista Brasileira de Estudos Políticos (Orlando Carvalho/diretor), Instituto de Investigaciones Sociales/UNAM (Lucio Mendieta y Núñez; Pablo González Casanova/diretores), Solar/Hachette (Gino Germani/indireto), Siglo XXI (Pablo González Casanova/ indireto).

I 2 O caso de José Medina Echavarría não se ajusta totalmente ao critério de organização do quadro, pois, embora nascido na Espanha, residiu em duas cidades nas quais publicou (México e Santiago de Chile). No entanto, decidimos incluí-lo porque conservou sua condição de estrangeiro e sua residência foi, em todos os casos, temporária. 
I3 Todos os gráficos e quadros deste artigo são de elaboração própria dos autores, de acordo com as bases de dados e as informações consultadas.

I4 Devemos indicar que, nesse momento, a publicação nas editoras Fondo de Cultura Económica e Siglo XXI, mexicanas, e Paidós, argentina, garantia uma circulação regional relativamente ampla, dada a sua importância como principais empresas exportadoras de livros de ciências sociais na América Latina.

I5 Antes, mas em edição de circulação restrita, veio a lume em inglês The Latin American in residence lectures (1969/I970) (University of Toronto).

I6 Para a identificação dos artigos e das resenhas, compulsamos a Síntese curricular e o Sumário biobliográfico de Florestan Fernandes, disponíveis em Fernandes (I996, 20Io), e as bases de dados Periódicos Capes, SocIndex, JStor e Fachinformationsdienst Romanistik. Para a identificação dos eventos internacionais, conferimos as informações cedidas pelo próprio Florestan Fernandes nas notas explicativas presentes nos capítulos de sua obra publicada em livro. Não fizemos aqui um levantamento sistemático dos capítulos de livro publicados no exterior devido à dificuldade de encontrar informações a respeito. Porém, ao longo do texto, faremos referências aos capítulos publicados por Fernandes na América Latina.

I7 Esse livro, cuja introdução é feita por Warren Dean, na verdade colige os cinco artigos que haviam saído na International Journal of Sociology, II/I-2, "Reflections on the Brazilian Counter-Revolution" (Spring-Summer, I98I). Daí o "pico" de artigos nesse ano.

I8 Esse livro saiu na coleção "Beiträge zur Soziologie und Sozialkunde Lateinamerikas", da editora alemã Gehlen, em que foram publicados vários livros sobre América Latina. Na mesma coleção, além dos dois volumes de A integração do negro na sociedade de classes, também saíram livros de Celso Furtado, Barbara Freitag, Alejandro Losada e outros.

I9 Existe uma versão em espanhol de Fundamentos empíricos da explicação sociológica, preparada pela UNAM. Contudo, segundo nossos registros, ela nunca foi publicada. Ignoramos as razões desse fato, bem como a data em que a tradução foi realizada. Podemos conjecturar a seguinte 
conexão: o livro de Florestan Fernandes traduzido pelos mexicanos havia sido motivo de elogio por parte de Robert K. Merton no "Post Scriptum" bibliográfico do ensaio "Funciones manifestas e latentes", incluído no livro Teoría y estructuras sociales, publicado em I964 pela coleção de sociologia da editora mexicana Fondo de Cultura Económica. A respeito dos possíveis promotores da publicação do livro de Fernandes no México, não temos indícios claros. Apenas cabe uma especulação. Publicado em São Paulo em I959, é mais que provável que o livro tenha chegado no México na virada para os anos 1960; nesse momento, as principais instituições de ciências sociais da Universidad Nacional Autónoma de México - a Escuela Nacional de Ciencias Políticas y Sociales, o Instituto de Investigaciones Sociales e a Revista Mexicana de Sociología - estavam sob o controle de Lucio Mendieta y Núñez e Pablo González Casanova (Blanco \& Jackson, 20I6). Podemos imaginar que a iniciativa partiu de algum deles, talvez para a coleção "Biblioteca de ensayos sociológicos", em que foram publicados no país asteca dois livros de Alberto Guerreiro Ramos - Sociología de la mortalidad infantil (1955) e La Reducción sociológica: introducción al estudio de la razón sociológica (I959) - e um de Evaristo de Moraes Filho - La Sociología de los opúsculos de Augusto Comte (I957). O único registro encontrado, para além da indicação disponível no Sumário do Curriculum de Florestan Fernandes (I996), em que a versão mexicana aparece sem data de publicação, é a edição de I986, pela editora mexicana Limusa. Nas cartas trocadas com Fernando Henrique Cardoso, mencionam-se também tentativas de publicar, pela Eudeba, de Buenos Aires, A sociologia numa era de revolução social (1963) (cf. carta de Fernando Henrique Cardoso a Florestan Fernandes, II/3/1965, Fundo Florestan Fernandes, Biblioteca Comunitária da Universidade Federal de São Carlos). Quer dizer: algumas tentativas de circulação mais efetiva da obra de Fernandes em dois lugares importantes para a difusão latino-americana da sociologia, a Argentina e o México, viram-se frustradas por razões que ignoramos.

20 Em 2008, saiu uma antologia em espanhol da obra de Florestan Fernandes na Colección Pensamiento Crítico Latinoamericano, da Clacso, organizada por Heloísa Fernandes, com o título Dominación y desigualdad: el dilema social latino-americano (Bogotá: Siglo del Hombre). 
2I As revistas marcadas com * na coluna "País" são editadas em mais de um país.

22 O Google Ngram é uma ferramenta de pesquisa que usa como fonte os livros digitalizados pelo Google Books. Ela permite medir a frequência de $n$-grams (sequências de caracteres separados por espaços) em um conjunto de textos. Há vários corpora disponíveis em vários idiomas (infelizmente, não temos para o português), sendo o de espanhol um dos maiores, com 45 bilhões de palavras (cf. http:// googlebooks.byu.edu/\#, acesso em 7 de agosto de 20I7). Como se trata de um universo de livros digitalizados pela Google, não podemos afirmar que se trata de amostra representativa da publicação em livro em espanhol. Além disso, não há como controlar os possíveis vieses presentes nesse corpus. Seus resultados, contudo, indicam certas tendências temporais que parecem consistentes com os resultados aqui levantados. Para o manifesto metodológico da culturonomics, que pretende renovar o campo das humanidades pela pesquisa informacional em big data, cf. Michel et al. (20II).

23 "No curso de ciências sociais esses pioneiros foram: André Gros (ciência política), René Poirier (filosofia), Maurice Bié (economia) Victor Tapié (história), Antoine Bom (história antiga; adepto da Escola Arqueológica de Atenas), Jean Gilbert (geografia humana) e Jacques Lambert (sociologia)" (Amorim, I999: 28). Cf. também Oliveira (I995).

24 O número de anos entre parêntesis indica o tempo de atuação profissional dos agentes, pois, em alguns casos, eles residiram no país por muito mais tempo, como Willems (i8 anos), ou pelo resto da vida, como Baldus.

25 No caso do Rio de Janeiro, apesar da presença entre I939I944 de Jacques Lambert à frente da cadeira de sociologia da Faculdade Nacional de Filosofia da Universidade do Brasil - e de seu regresso, em I958, como expert da Unesco no Centro Brasileiro de Pesquisas Educacionais (CBPE) -, seu impacto nas ciências sociais locais acabou concentrando-se apenas na formação de Luiz de Aguiar Costa Pinto, que havia sido seu assistente - porém, ele não teve a possibilidade de sucedê-lo na cadeira (que foi ocupada durante 20 anos pelo outro assistente, Hildebrando Leal, que pouco contribuiu para o avanço da disciplina na antiga capital federal). 
$26 \mathrm{Na}$ Universidade do Brasil, também havia a possibilidade de fazer o doutoramento em ciências sociais, que era obtido em decorrência do concurso de livre-docência (Amorim, I999). Dos contemporâneos de Florestan Fernandes, apenas Evaristo de Moraes Filho e Luiz de Aguiar Costa Pinto obtiveram o título de doutor em sociologia na Faculdade Nacional de Filosofia da Universidade do Brasil (FNFi/UB). Costa Pinto, aliás, tencionava fazer o doutorado em Chicago, com Everett Hughes, por intermédio de contatos com Donald Pierson, mas isso não foi possível diante da negativa do visto da Embaixada dos Estados Unidos, por motivos políticos (Maio \& Lopes, 2015).

27 Esse uso simultâneo das duas instituições, a USP e a ELSP, contudo, não era generalizado. Da geração contemporânea a Florestan Fernandes, podemos mencionar alguns casos contrastantes. Maria Isaura Pereira de Queiroz e Ruy Coelho, por exemplo, que atuaram longamente na cadeira de sociologia II da USP, fizeram seu doutoramento no exterior, na França e nos Estados Unidos, respectivamente. Antonio Candido fez diretamente o seu doutorado na USP, em I954, depois de já ter obtido a livre-docência com o concurso que prestou para a cadeira de literatura brasileira em I945. Gioconda Mussolini, assistente da cadeira de antropologia, também fez o mestrado na ELSP, mas não chegou a concluir seu doutorado na USP. Mario Wagner Vieira da Cunha, Juarez Brandão Lopes e Oracy Nogueira, por sua vez, fizeram a pós-graduação na University of Chicago, graças à mediação de Donald Pierson. Essa variedade de possibilidades indica que, também em São Paulo, a formação no exterior era um caminho possível, mas não exclusivo, para os praticantes das ciências sociais.

28 Enquanto em São Paulo, a Escola Livre de Sociologia e Política e a Faculdade de Filosofia, Ciências e Letras da USP oferecem essa possibilidade desde, respectivamente, I934 e I935 - e, ainda no caso brasileiro, nas Universidades do Distrito Federal e do Brasil, no Rio Janeiro, também na década de I930 -, no México, uma formação de graduação em sociologia somente será possível quase 20 anos mais tarde, com a criação, em I95I, da Escuela Nacional de Ciencias Políticas y Sociales (mais tarde denominada Faculdade de Ciencias Politicas y Sociales) da Universidad Nacional Autónoma de México. O mesmo ocorre nos de- 
mais países da região: na Argentina, em 1957, com a criação do curso e do departamento de sociologia na Universidad de Buenos Aires; no Chile, em 1958, com a criação da Escuela de Sociología da Facultad de Filosofía y Educación da Universidad de Chile e da Escuela de Sociología da Universidad Católica de Chile; na Colômbia, em I959, com a criação da Facultad de Ciencias Sociales da Universidad Nacional de Colombia.

$29 \mathrm{Em}$ El Colegio de México, houve uma tentativa pioneira, mas que não teve êxito, levada a cabo por José Medina Echavarría e Cosío Villegas, com a criação, em I943, do Centro de Estudios Sociales (CES), do qual Medina Echavarría foi o primeiro e único diretor. O CES oferecia programa de pós-graduação de quatro anos que articulava sociologia, economia e política. Por razões diversas, mas fundamentalmente financeiras, o programa fechou as portas em I946 (Morcillo Laíz, 2008). Dos i8 estudantes que integraram a primeira e única coorte, somente dois se formaram. Trinta anos mais tarde, El Colegio de Mexico refundou o CES como Centro de Estudios Sociológicos.

30 Pablo González Casanova [1922], Sorbonne e Université de Paris; Francisco López Cámara [I926-I994],Université de Paris; Enrique González Pedrero [1930], Institut d’Études Politiques e Sorbonne, Université de Paris; Arturo González Cosío [I930], Colonia, Alemanha; Víctor Flores Olea [1932], Università di Roma, Institut d'Études Politiques, Université de Paris e London School of Economics; Rodolfo Stavenhagen [1932-2016], University of Chicago, Université de Paris; Raúl Benítez Zenteno [193I-2006], Centro Latinoamericano y Caribeño de Demografía (Cepal), Chile.

3I Fernando Henrique Cardoso foi para o Chile, em I964, tornando-se funcionário do Ilpes (Cepal) e da Flacso, embora tenha realizado breve estada em Paris em 1962-1963, por convite de Alain Touraine (Garcia Jr., 2004); Maria Sylvia de Carvalho Franco realizou pós-doutorado na Yale University, em 1969; Marialice Mencarini Foracchi deu conferências na Columbia University, em I966, em Porto Rico, em 1967, e na University of Southern California, em I969.

32 Apenas a título de exemplo, na Argentina, a primeira revista especializada, o Boletín del Instituto de Sociología, foi publicada regularmente entre I942 e I947. Em I96I, I4 
anos mais tarde, apareceu Desarrollo Económico, que se converteria na revista de ciências sociais de maior prestígio do país. No México, a Revista Mexicana de Sociología (I939) e Ciencias Políticas y Sociales (1955) foram, até muito recentemente, as únicas revistas especializadas.

33 A fim de esclarecer melhor esse ponto, nossa intenção não é colocar à prova de modo sistemático as relações entre duas variáveis - "circulação internacional" e "internacionalização" -, e sim mostrar que, à luz do caso de Florestan, suas relações podem ser contingentes e historicamente cambiantes.

34 Uma hipótese adicional, que poderia também ser aventada aqui, é a relação entre circulação internacional e a origem social desses sociólogos. À exceção de Gino Germani, de origem modesta, todos os outros aqui escolhidos para compor um quadro de referência para a análise de Fernandes - José Medina Echavarría, Luiz de Aguiar Costa Pinto, Aldo Solari, Pablo González Casanova e Orlando Fals Borda - tinham origem social relativamente vantajosa. Se é possível conjecturar que essa posição no espaço social inscreveu neles disposições favoráveis à circulação, a origem social modesta de Fernandes provavelmente se associou a certa insegurança de transitar fora do país. Infelizmente, não teremos espaço para aprofundar neste texto as condicionantes de classe da circulação internacional.

35 "O dr. [Peter] Heintz [da Flacso] foi e veio, mas não me mandou uma decisão em tempo oportuno. No Rio [durante o seminário do Clacps de 1965], quando rebentou o segundo escândalo em torno dos nossos nomes, recebi vários convites importantes para trabalhar no exterior. Um dos melhores, partiu do Wagley; depois recebi outro igualmente bom de Yale (pelo Morse), mas já estava assim pela Columbia" (carta de Florestan Fernandes a Fernando Henrique Cardoso, 24/6/1965, Arquivo FHC).

36 Florestan Fernandes chega a dizer que os especialistas norte-americanos deveriam fazer "com urgência, uma revolução copernicana em sua perspectiva de observação e de análise", pois nada justificaria, "principalmente depois do promissor desenvolvimento das ciências sociais nos principais centros [...] da América Latina, que se mantenham velhos estereótipos sobre o significado e o alcan- 
ce dos avanços autóctones da pesquisa social naqueles centros" (Fernandes, I965: I50).

37 Um episódio contado em entrevista por Gabriel Conh é ilustrativo disso: ao inteirar-se de que Cohn havia sido convidado para estudar na Flacso, Fernandes reage da seguinte forma: "Você pode ir, mas para cá não volta" (Bastos et al., 2006: II9). Ainda segundo Cohn, isso não revelava uma intransigência, mas uma orientação de Fernandes que "apostava tudo na formação sólida e na experiência local antes de expor-se aos centros em que se construía uma nova hegemonia".

\section{REFERÊNCIAS BIBLIOGRÁFICAS}

Amorim, Maria Stella (I999). Costa Pinto e a missão sociológica. In: Maio, Marcos Chor \& Villas Bôas, Glaucia (orgs.). Ideais de modernidade e sociologia no Brasil. Porto Alegre: Ed. UFRGS, p. 23-38.

Arruda, Maria Arminda do Nascimento. (200I). Metrópole e cultura: São Paulo no meio do século XX. Bauru: Edusc.

Bastos, Elide Rugai. (20II). Atualidade do pensamento social brasileiro. Sociedade e estado, 26/2, p. 5I-70.

Bastos, Elide Rugai. (2002). Pensamento social da escola sociológica paulista. In: Miceli, Sergio (org.). O que ler na ciência social brasileira,1970-2002. São Paulo: Sumaré, p. I83-232.

Bastos, Elide Rugai et al. (2006). Conversas com sociólogos brasileiros. São Paulo: Ed. 34.

Blanco, Alejandro. (2009). Karl Mannheim en la formación de la sociología moderna en América latina, Estudios Sociológicos, 27/80, Ciudad de México, p. 393-43I.

Blanco, Alejandro. (2007). Ciências sociais no Cone Sul e a gênese de uma elite intelectual (I940-I965), Tempo Social, São Paulo, I9/I, p. 89-II4.

Blanco, Alejandro. (2006). Razón y modernidad. Gino Germani y la sociología en la Argentina, Buenos Aires: Siglo XXI.

Blanco, Alejandro \& Jackson, Luiz Carlos. (2016). O caudilho da sociologia mexicana: Pablo González Casanova e A democracia no México". Tempo Social, 28/3, pp. II7-I43. 
Blanco, Alejandro \& Jackson, Luiz Carlos. (2014a). Florestan Fernandes no espelho de Gino Germani. Sociologia \& Antropologia, Rio de Janeiro, 4/I, p. I27-I6I.

Blanco, Alejandro \& Jackson, Luiz Carlos. (20I4b). Sociologia no espelho. Ensaístas, cientistas sociais e críticos literários no Brasil e na Argentina (I930-I970). São Paulo: Ed. 34.

Blanco, Alejandro \& Sorá, Gustavo. (No prelo). Unity and fragmentation in the social sciences in Latin America. In: Heilbron, Johan; Sorá, Gustavo \& Boncourt, Thibaud (eds.). The social and human sciences in a global perspective, v. 2 . London: Palgrave Mcmillan (Socio-historical studies of the social and human sciences).

Blanco, Alejandro \& Wilkis, Ariel. (No prelo). The internationalization of sociology in Argentina, I985-20I5: geographies and trends. In: Heilbron, Johan; Sorá, Gustavo \& Boncourt, Thibaud (eds.). The social and human sciences in a global perspective, v. 2. London: Palgrave Mcmillan (Socio-historical studies of the social and human sciences).

Brasil Jr., Antonio. (2013). Passagens para a teoria sociológica: Florestan Fernandes e Gino Germani. São Paulo/Buenos Aires: Hucitec/Clacso.

Brasil Jr., Antonio \& Botelho, A. (20I7). Florestan Fernandes para dimensionar a força do presente. In: Starling, Heloísa Maria Murgel \& Botelho, André (orgs.). Impasses do Brasil contemporâneo. Belo Horizonte: Ed. UFMG.

Bringel, Breno et al. (2015). Notas sobre o Clapcs na 'era Costa Pinto' (I957-I96I): construção institucional, circulação intelectual e pesquisas sobre América Latina no Brasil. Dossiê Temático, 5 - Sociologia latino-americana II: desenvolvimento e atualidade, p. Iо-І8.

Cataño, Gonzalo. (2008). Orlado Fals Borda, sociólogo del compromiso. Revista de Economía Institucional, Io/19, p. 79-98. Cataño, Gonzalo. (1987). La sociología en Colombia, balance crítico. Bogotá: Plaza \& Janes.

Cohn, Gabriel. (2005). Florestan Fernandes e o radicalismo plebeu em sociologia. Estudos Avançados, I9/55, p. 245-250. Fernandes, Florestan. (2010). Sumário biobibliográfico [preparado por Duarcides Mariosa]. In: Leituras e legados. São Paulo: Global, p. 353-374. 
Fernandes, Florestan. (2006) [1975]. A revolução burguesa no Brasil: ensaio de interpretação sociológica. São Paulo: Globo. Fernandes, Florestan. (I996). Sumário do curriculum de Florestan Fernandes. Estudos Avançados, Io/26, p. 55-56. Fernandes, Florestan. (I98I) [I973]. Capitalismo dependente e classes sociais na América Latina. Rio de Janeiro: Zahar.

Fernandes, Florestan. (I978). A condição de sociólogo. São Paulo: Hucitec.

Fernandes, Florestan. (1977). A sociologia no Brasil: contribuição para o estudo de sua formação e desenvolvimento. Petrópolis: Vozes.

Fernandes, Florestan. (1975) [1968]. Sociedade de classes e subdesenvolvimento. Rio de Janeiro: Zahar.

Florestan, Florestan. (I973). Problemas de conceptualización de las clases sociales en América Latina. In: Zenteno, Raul Benitez. Las clases sociales en América Latina. Ciudad de México: Siglo XXI.

Fernandes, Florestan. (1965). As ciências sociais na América Latina. In: Clapcs. As ciências sociais na América Latina. São Paulo: Difel.

Ferreira, Janaína. (1999). Resistências à mudança: um debate dos cientistas sociais na década de 50. Dissertação de Mestrado. PPGSA/Universidade Federal do Rio de Janeiro.

Franco, Rolando. (2007). La Flacso clásica (1957-I973). Vicisitudes de las ciencias sociales latinoamericanas. Santiago: Editorial Catalonia/Flacso-Chile.

Garcia Jr., Afrânio. (2004). A dependência da política: Fernando Henrique Cardoso e a sociologia no Brasil. Tempo Social, I6/I, p. 285-300.

Graciarena, Jorge. (1973). Comentario [a la propuesta de Fernández]. In: Zenteno, Raul Benitez. Las clases sociales en América Latina. Ciudad de México: Siglo XXI.

Grisendi, Rodolfo Ezequiel. (20I4). El centro de la periferia: internacionalización de las ciencias sociales y redes académicas latinoamericanas. Manuel Diégues Júnior y los avatares de la sociología del desarrollo. Crítica e Sociedade, Uberlândia, 4/2, p. I48-167.

Jackson, Luiz Carlos. (2004). A sociología paulista nas revistas especializadas (I940-I965). Tempo Social, São Paulo, I6/I, p. $263-283$. 
Jaramillo, Jaime Eduardo. (2010). Antología de Orlando Fals Borda. Madrid: Agencia Española de Cooperación Internacional para el Desarrollo.

Jaramillo, Jaime Eduardo. (2006). La institucionalización de los saberes en la Facultad de Ciencias Humanas (U.N.): el proceso de gestación y la lucha por la autonomía de los campos disciplinarios. In: Archila, Mauricio et al. (orgs.). Facultad de Ciencias Humanas: Cuatro décadas de compromiso académico en la construcción de la nación. Bogotá: Edigraf, p. 442-445. Lopez, Matias \& Araujo, Mateus Donato Amorim de. (20II). Desenvolvimento e narrativas de modernidade: Costa Pinto e a construção de uma sociologia transnacional para o terceiro mundo. Revista Aurora, Marília, 4/2, p. 213-225. Maio, Marcos Chor \& Lopes, Tiago da Costa. (2015). 'For the establishment of the social disciplines as sciences': Donald Pierson e as ciências sociais no Rio de Janeiro (I942-I949). Sociologia \& Antropologia, 5/2, p. 343-380.

Miceli, Sergio. (1989). Condicionantes do desenvolvimento das ciências sociais. In: Miceli, Sergio. História das ciências sociais no Brasil, v. I. São Paulo: Sumaré/Idesp/Fapesp, p. 9I-I33.

Michel, Jean-Baptiste et al. (20II). Quantitative analysis of culture using millions of digitized books. Science, Washington, 33I/60I4, p. I76-I82.

Morcillo Laíz, Álvaro. (2008). Historia de un fracaso: individuos, organizaciones y la sociología weberiana en México (I937-I957), Sociológica, México, 67, p. I49-I92.

Oliveira, Lucia Lippi. (1995). As ciências sociais no Rio de Janeiro. In: Miceli, Sergio. História das ciências sociais no Brasil, v. 2. São Paulo: Sumaré/Idesp/Fapesp, p. 233-307.

Peixoto, Fernanda. (1989). Franceses e norte-americanos nas ciências sociais brasileiras (I930-I960). In: Miceli, Sergio. História das ciências sociais no Brasil, v. I. São Paulo: Sumaré/Idesp/Fapesp, p. 477-532.

Restrepo Forero, Gabriel Adolfo. (2002). Peregrinación en pos de omega: sociología y sociedad en Colombia. Bogotá: Universidad Nacional de Colombia.

Romão, Wagner de Melo. (2006). A experiência do Cesit: sociologia e política acadêmica nos anos ig6o. São Paulo: Humanitas. 
Palavras-chave Florestan Fernandes; circulação internacional; internacionalização; trajetória intelectual; América Latina.

\section{Keywords}

Florestan Fernandes; international circulation; internationalization; intellectual trajectory; Latin America.

\section{A CIRCULAÇÃO INTERNACIONAL DE FLORESTAN FERNANDES}

\section{Resumo}

O artigo examina a obra e a trajetória de Florestan Fernandes sob ângulo até hoje pouco explorado: sua circulação internacional. A análise é baseada em três eixos: (I) identificação das especificidades da circulação internacional de Florestan Fernandes à luz da trajetória modal dos sociólogos de sua geração que lideraram a formação da disciplina na América Latina; (2) o mapeamento da circulação de sua produção intelectual fora do Brasil, tomando como referência seus artigos publicados em revistas estrangeiras, sua participação em eventos científicos internacionais e as resenhas de suas obras feitas no exterior; (3) o delineamento de algumas hipóteses explicativas, que incidem na necessidade de distinguir conceitualmente os termos "internacionalização" e "circulação internacional", a fim de explicar o caso de Florestan Fernandes. Ao final, oferecemos algumas indicações sobre os possíveis efeitos da circulação internacional de Fernandes em sua teorização sociológica da América Latina.

\section{THE INTERNATIONAL CIRCULATION OF FLORESTAN FERNANDES}

\section{Abstract}

This article analyses the international circulation of the work of sociologist Florestan Fernandes - an aspect that has been somewhat overlooked. The paper focuses on three aspects of this problem: (I) it highlights the singularities of the international circulation of Fernandes's work vis-à- vis the modal trajectory of the scholars who led the formation of the discipline in Latin America; (2) it analyses his publications in foreign journals, his participation in international scientific events, and the reviews of his works made outside Brazil, data from which is used to map the international circulation of his work; (3) in order to explain the case of Florestan Fernandes, it offers some explanatory hypotheses focused on the conceptual distinction between the terms 'internationalization' and 'international circulation.' Finally, the article makes some suggestions concerning the impact of the international circulation of Fernandes's work on his own sociological theorization of the peculiarities of Latin America. 